\title{
The Tostan program: Evaluation of a community based education program in Senegal
}

\author{
Nafissatou J. Diop \\ Population Council \\ Modou Mbacke Faye \\ Amadou Moreau \\ Jacqueline Cabral \\ Helene Benga
}

See next page for additional authors

Follow this and additional works at: https://knowledgecommons.popcouncil.org/departments_sbsr-rh

Part of the Community-Based Research Commons, Demography, Population, and Ecology Commons, Gender and Sexuality Commons, International Public Health Commons, Public Health Education and Promotion Commons, and the Women's Health Commons How does access to this work benefit you? Let us know!

\section{Recommended Citation}

Diop, Nafissatou J., Modou Mbacke Faye, Amadou Moreau, Jacqueline Cabral, Helene Benga, Fatou Cisse, Babacar Mane, Inge Baumgarten, and Molly Melching. 2004. "The Tostan program: Evaluation of a community based education program in Senegal," FRONTIERS Final Report. Washington, DC: Population Council. 


\section{Authors}

Nafissatou J. Diop, Modou Mbacke Faye, Amadou Moreau, Jacqueline Cabral, Helene Benga, Fatou Cisse, Babacar Mane, Inge Baumgarten, and Molly Melching 


\title{
The TOSTAN Program Evaluation of a Community Based Education Program in Senegal
}

\author{
Nafissatou J. Diop, Modou Mbacke Faye, Amadou Moreau \\ Jacqueline Cabral, Hélène Benga, Fatou Cissé \\ Babacar Mané, Inge Baumgarten, and Molly Melching \\ Population Council \\ GTZ \\ TOSTAN
}

August 2004

This study was funded by the US Agency for International Development (USAID), under Cooperative Agreement No. HRN-A-00-98-00012-00 and Population Council in-house project 580313046 . The opinions expressed are the responsibility of the authors and do not necessarily reflect the views of the US Agency for International Development. 


\section{Summary}

This operations research project evaluated the effect and impact of a basic education program, developed by TOSTAN, a non-governmental organization based at Thiès, Senegal. The basic education program consists of four modules: hygiene, problem solving, women's health, and human rights. Through these four themes, emphasis was placed on enabling the participants, who were mostly women, to analyze their own situation more effectively and thus find the best solutions for themselves. The Supra Regional Project for the Elimination of Female Genital Cutting of GTZ funded implementation of the program in 90 villages in Kolda Region, and the Population Council's Frontiers in Reproductive Health Program, with funding from USAID, used this opportunity to evaluate the program in 20 villages.

All women and men participating in the education program were interviewed before and after the intervention, and again two years later, to measure women's and men's awareness, attitudes and behavior concerning reproductive health (RH) and female genital cutting (FGC). A group of women and men from 20 similar villages that did not receive the education program were interviewed at the same time to serve as a comparison group. To test the impact of the program on community members' willingness to abandon FGC, the proportion of respondents' daughters aged 0 to 10 years whose parents reported they had been cut was used as the primary outcome indicator.

The education program significantly increased the awareness of women and men about human rights, gender-based violence, FGC and reproductive health, but awareness of human rights, violence and FGC also increased in the comparison site, although to a lesser extent. The consequences of FGC were better known, as were issues concerning contraception, pregnancy surveillance and child survival. In general, women's knowledge improved more than men's, except for STI/HIV. Diffusion of information from the education program within villages worked well, as other women and men living in the intervention villages also increased their knowledge on most indicators. For all indicators, apart from those concerning violence, the experimental group improved significantly more than the comparison group.

Attitudes improved significantly in the experimental group, with women and men denouncing discrimination, violence and FGC. Attitudes towards FGC also improved significantly in the comparison group, but to a lesser extent than in the experimental group. There was a dramatic decrease in the approval of FGC, although a small proportion of women (16\%) participating in the program did not change their attitude. Regret for having cut their daughters increased and fewer women were willing to cut their daughters in the future. Women perceived men's attitudes towards contraception as improving. However, the intervention group showed higher levels of positive attitudes than the comparison group.

There also appears to have been a positive improvement in behavior in terms of FGC and some aspects of reproductive health. The prevalence of FGC reported among daughters aged $0-10$ years decreased significantly among women directly and indirectly exposed to the program. Life table analysis confirmed this change in the intervention group, but also that the girls who were cut were being cut earlier than before.

No change in use of contraception was observed over time, but pregnancy surveillance and use of delivery services improved compared with the comparison group, although delivery in health facilities remained low because of their inaccessibility. Communities have mobilized around maintaining peace and reducing discrimination, through establishment of committees for peace and management of conflicts. 
A public declaration to support abandonment of FGC took place in 2002 to reinforce these changes in attitudes and behavior. Representatives from approximately 300 villages gathered in Karcia to denounce the practice. The forum organized by young girls was an opportunity to express strongly their opposition to FGC, and early and forced marriage. Although only a small proportion of people from the intervention villages attended this event, those men and women who attended expressed confidence that the declaration would be respected and that no more girls would be cut in those villages. Overall, women were more confident than men, but women who were indirectly exposed to the program were less confident.

The communities recommended that the IEC campaigns should be continued, and men would like to see the new law against FGC applied. Those from the Mandingo ethnic group seem more willing to abandon the practice than those from the Pulaar ethnic group, which may be due to the influence of the Pulaar religious leader who was not in favor of abandonment.

In conclusion, the impact of the TOSTAN program on women and men's well being has been substantial. The program has been able to bring about a social change within the community and to mobilize the villagers for better environmental hygiene, respect for human rights and improvement of health, as well as specifically reducing support for and practice of FGC. Extending the TOSTAN program to other areas of Senegal and to other African countries could make a difference to the well being of women and of the community as a whole. 


\section{Acknowledgements}

We would like to express our sincere thanks to all whose work has contributed to the completion of the study. Above all, we acknowledge the full cooperation of the NGO TOSTAN, as well as the willingness of all its staff members to provide the information necessary for the study.

We would also record the support of OFAD-NAFOORE's team at Bagadadji, which greatly helped the fieldwork.

The support of UNFPA/Senegal contributed to finalizing the study report. We want to thank them for their financial contribution.

Special thanks must go to the whole research team, which consisted of:

- Amadou Tall

- The interviewers who collected information in the villages

- The supervisory team

- The personnel who entered and processed the quantitative and qualitative data

The involvement of the regional authorities in Kolda contributed to successful implementation of the study. We express our thanks to:

- The Regional Chief Medical Officer

- The Prefects and Sub-Prefects in the Departments of Kolda, Sédhiou and Vélingara

- The Commander of the 6th Military District

- The staff of the Statistical Service in Kolda Region

- All the local team of the Community Development Service

This acknowledgement would not be complete without mentioning the participation of the communities who were involved in the research. This report could not have been made without their cooperation. 


\section{Contents}

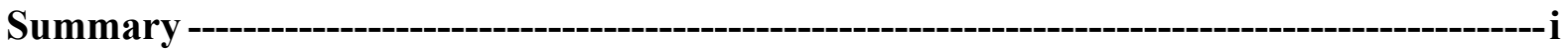

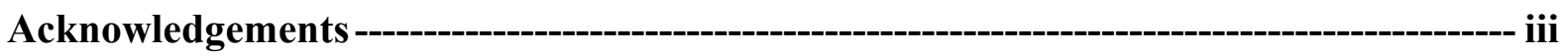

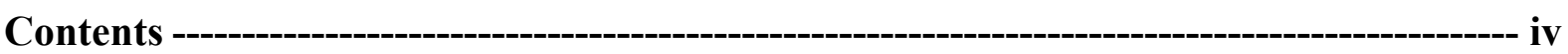

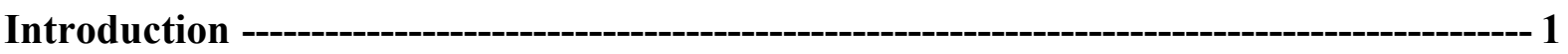

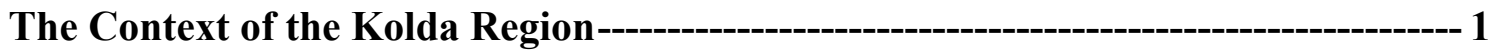

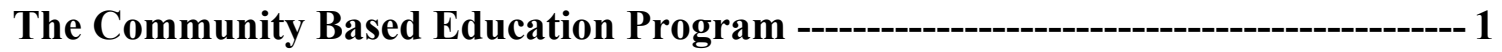

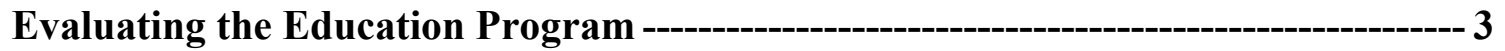

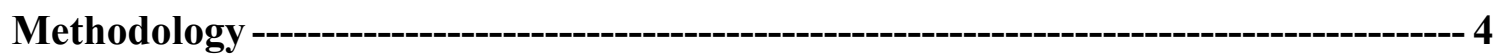

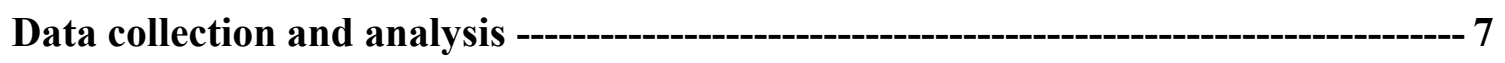

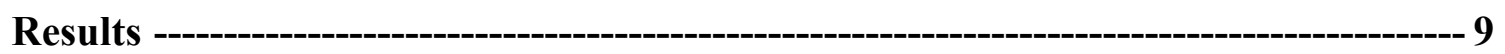

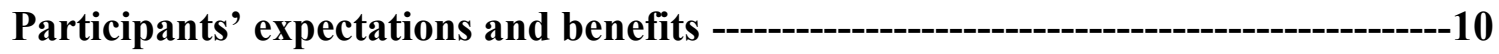

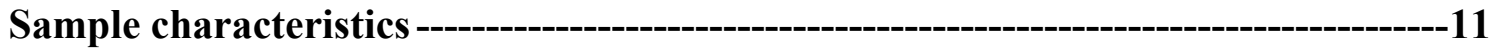

Contribution of the Program to Awareness, Attitudes and Behavior ---------------------11

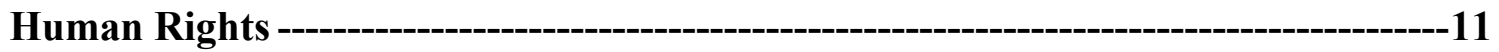

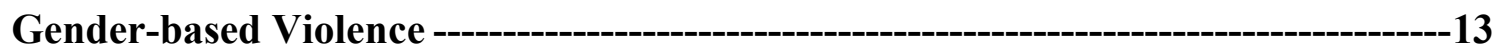

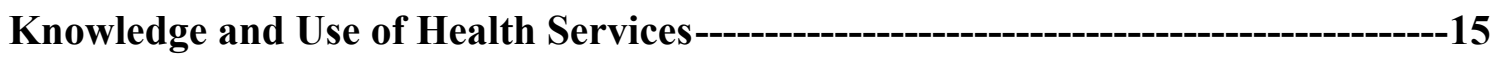

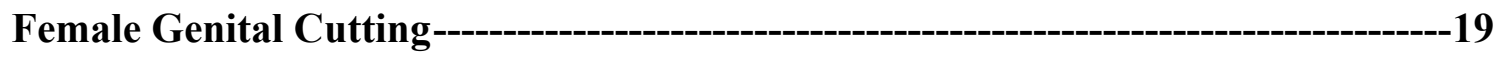

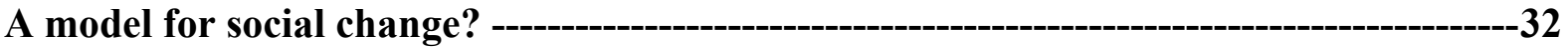

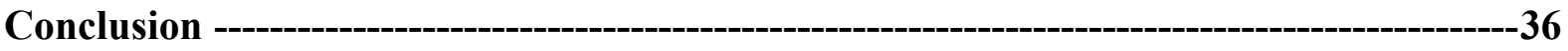

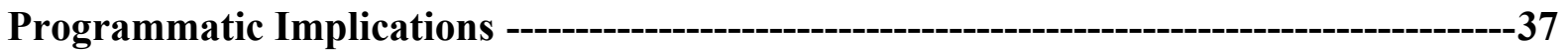

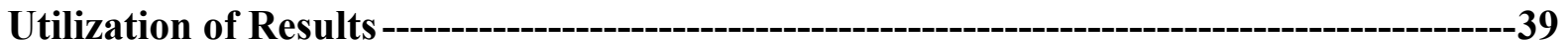

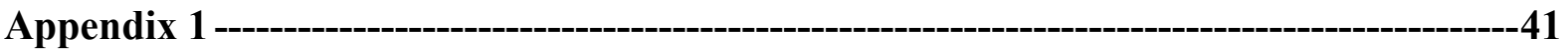

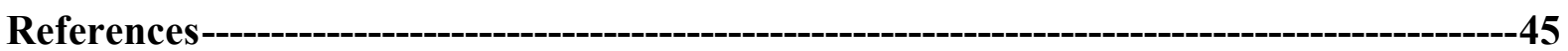




\section{Introduction}

This operations research project evaluated the effect and impact of a basic education program, developed by TOSTAN, a non-governmental organization based at Thiès. The education program consists of four modules: hygiene, problem solving, women's health and human rights. Through these four themes, emphasis was placed on enabling the participants, who were mostly women, to analyze their own situation more effectively and thus find the best solutions for themselves. TOSTAN's approach was based on peaceful social change through a basic community education program and a process of social mobilization. The Supra Regional Project for the Elimination of Female Genital Cutting (FGC) of GTZ funded implementation of the program in 90 villages in the Region of Kolda, starting in 2001. With funding from USAID, the Population Council's Frontiers in Reproductive Health Program used this opportunity to evaluate the effects and impact of the program.

\section{The Context of the Kolda Region}

About 8.6 percent of the Senegalese population lives in the Kolda Region. Kolda's annual population growth rate is high (3\%), principally due to a high level of fertility ( 7 children per woman) and low use of contraceptives (1\%). Early marriage is the norm among both men (25 years) and women (17 years).

The Kolda Region is economically and socially under-developed. It lacks economic potential, which restricts the provision of services to meet basic needs, leading to a low standard of living. In the rural areas, 57 percent of households live below the poverty line, compared with 25 percent in urban areas. Serious gender disparities exist, resulting in even greater economic hardship among women. Female genital cutting is estimated to be practiced widely (approximately 88\%) among women in the Region (Bop, 1999).

The Kolda Region has a poorly developed health infrastructure and lacks qualified personnel, leading to inadequate provision of medical services to the population, and especially to women and children. The Kolda region has one doctor for every 86,117 inhabitants and one state nurse and one registered midwife for every 13,205 women of reproductive age, whereas for the country as a whole, the ratios are one doctor for every 12,700 people, one state nurse for 4,300 people and one midwife for every 3,283 women of reproductive age. According to the UNDP Report on Human Development, 88.5 percent of the population is without access to health care (UNDP, 1998), and only 38 percent of births in 1999 took place with any kind of medical assistance. The level of maternal mortality is particularly high $(1,225$ per 100,000 live births).

The position of children in this region is also poor; malnutrition affects 34 percent of all children, compared with 22 percent nationally. This contributes to a high infant and child mortality rate of 198 per 1,000, compared with 154 per 1,000 nationally. The region remains an endemic area for malaria, which also contributes to the high morbidity rate.

Illiteracy is particularly high, at around 90 percent of the population, which, together with its geographical isolation, seriously limits access to information and to the media. 


\section{The Community Based Education Program}

TOSTAN's activities in the Kolda Region started in 1988, when UNICEF financed an experimental program of informal education for the development of the Pulaar language in 20 villages in the Departments of Kolda and Vélingara. The results of this experimental program were so popular with the local people and the regional authorities that TOSTAN was requested to extend the program to more communities.

TOSTAN thus returned in 1996 to cooperate with a newly formed local NGO, KORASE, in launching an education program in the context of the pilot phase of PAPF, financed by the World Bank in 14 communities around Médina Chérif in Kolda. This education program led to the first public declaration in the Kolda Region on June 2, 1998 of the abandonment of FGC and of early marriage. TOSTAN then sought and obtained support for extending the program further, again in cooperation with KORASE, to 23 more villages in the same area. UNICEF financed TOSTAN and at the same time, KORASE received funds from CEDPA to introduce the first part of the education program covering human rights, problem solving, health and environmental hygiene in 30 villages, in cooperation with another NGO, OFADNAFOORE. These two interventions led to two more public declarations, on November 27, 1999 at Bagadadji including 105 communities, and on March 25, 2001 at Mampatim including 108 villages.

To sustain and build on this movement for abandoning FGC in an area where it was practiced by almost 90 percent of women, TOSTAN sought and received funding from GTZ for a project carried out as follows:

- 90 communities were identified by TOSTAN, OFAD-NAFOORE and by local staff from the Ministries of Health and of the Family;

- A social mapping study of these 90 communities was undertaken by TOSTAN's local staff;

- Senior staff (coordinator, supervisors and facilitators) from OFAD were trained in all aspects of TOSTAN's basic education program, including teaching, administration, strategies for introduction, follow-up and evaluation;

- Community Management Committees were trained by the nine supervisors;

- One facilitator per community trained 30 participants in each community in the Pulaar and Mandingo languages. Classes, each of two hours, were held three times a week. From January to June 2001, classes covered human rights, problem solving and hygiene. During the rainy season, participants were given books to help them revise and remember what they had learned in their classes, and they also carried out social mobilization activities. A total of 2,339 women and 221 men participated in the program.

- Follow-up of the classes in all 90 villages was undertaken by the coordinator, the supervisors, by members of OFAD-NAFOORE's staff and by TOSTAN's instructors;

- Inter-village meetings were held by the community management committees to exchange experiences and to take decisions concerning collective actions;

- Information and social mobilization activities were held in the 90 villages and in other neighboring communities by local staff of the Ministries of Health and of the Family; 
- A public declaration was organized at Karcia on June 5, 2002, to declare the abandonment of FGC by 300 villages.

These activities were implemented through the following strategies:

- Involvement in project activities of local staff from the Ministries of Health and of the Family;

- Informing the traditional and religious leaders and the elected politicians of the area about project activities;

- Cooperation with, and building capacity of, a local NGO to carry out the project developed by TOSTAN;

- Choosing 10 neighboring villages in each targeted area to pursue social transformation of the area;

- Selection of facilitators and supervisors from the communities that participate in the program;

- Setting up and training community management committees to manage project activities and to ensure that progress can be sustained;

- Holding inter-village meetings in support of the project aims and to confirm collective decisions;

- Holding a Public Declaration.

Since 1997, TOSTAN has organized a public declaration by a large group of villages that have agreed to abandon FGC as a strategy to enable the people themselves to renounce a traditional practice without fear of social stigma. The declaration is not intended as an end in itself, but constitutes an important step in the process of finally abandoning FGC. The declaration is seen as a way of promoting human dignity, human rights and the health of girls and women. It is intended as a positive step, which should be a joyful occasion that reinforces the positive aspects of traditions as it marks an important moment in the life of the communities.

TOSTAN is aware that in launching any significant social movement that is intended to bring about profound changes, a small group of informed and enlightened people will be the first to commit themselves in the name of the community as a whole. Others will remain hesitant and skeptical. It is likely, also, that a small proportion within the community will remain opponents to this change, but it is anticipated that eventually the new behavior (i.e. not practicing FGC) will become the norm, rather than being practiced by a minority. TOSTAN has come to acknowledge the essential contribution to the process of social change made by this declaration, and so it is essential that the communities themselves consciously and actively pursue the process from within.

\section{Evaluating the Education Program}

\section{Study objectives}

The overall objective of the evaluation was to provide information to support a strategy for improving women's health and for abandonment of the practice of FGC.

The specific aims were: 
1. To assess the effect of TOSTAN's basic education program on people's knowledge, beliefs and attitudes concerning reproductive health issues and human rights;

2. To assess the effect of TOSTAN's basic education program on people's awareness of the negative consequences and human rights issues associated with FGC;

3. To determine the factors that lead to changes in social attitudes towards FGC;

4. To assess the combined effects of TOSTAN's basic education program and community mobilization activities on the willingness of community members to abandon the practice of FGC.

\section{Hypotheses}

1. Women who have attended a basic education program will have higher levels of knowledge about, and more positive attitudes towards, reproductive health (including FGC) and human rights than women who have not attended a basic education program.

2. Partners of women who have attended a basic education program will have higher levels of knowledge about the negative consequences of female genital cutting and be more in favor of abandoning the practice.

3. Women and men in communities in which women have attended a basic education program will have higher levels of knowledge about the negative consequences of FGC and will be more likely to make a public declaration abandoning female genital cutting than women and men in communities where no such program has been undertaken.

4. Women and men in communities in which women have undertaken a basic education program and in which a community mobilization process has been completed will be more likely to abandon the practice.

\section{Methodology}

Design

A quasi-experimental design was used, in which women and men living in the 20 intervention villages were compared with women and men living in 20 similar comparison villages. The effect of the intervention was measured by interviewing the following groups:

- Women and men directly exposed to the intervention, i.e. those who participated in the education program.

- Women and men indirectly exposed to the intervention, i.e. those living in villages where the education program was implemented but who did not themselves participate in the program.

- Women and men not exposed to the intervention, i.e. those living in the comparison villages.

To control for potential influences beyond the intervention, women and men from 20 comparison villages that did not receive the education program were interviewed. Those living in the 20 intervention villages, both participants and non-participants, were interviewed three times: at baseline immediately before the intervention was implemented; immediately after the intervention was completed; and once more at endline after two years. Those living 
in the comparison villages were interviewed twice, at baseline and endline. The design is shown diagrammatically on page 5 .

Intervention villages

Comparison villages

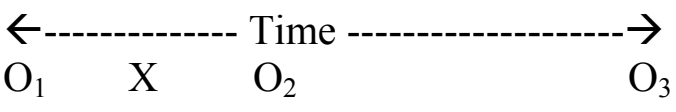

$\mathrm{O}_{4}$

Where:

$\mathrm{X}=$ basic education program and social mobilization process

$\mathrm{O}_{1}, \mathrm{O}_{4}=\quad$ measures of awareness about reproductive health, human rights and attitudes and intentions towards FGC among women and men participating in the basic education program, among women men living in the villages and not participating in the program, among women and men in the comparison communities measures of the proportion of girls aged 0-10 not cut.

$\mathrm{O}_{2}=$ measures of awareness about reproductive health, human rights and attitudes towards FGC among women and men participating in the basic education program, and among women men living in the villages and not participating in the program.

$\mathrm{O}_{3}, \mathrm{O}_{5}=\quad$ measures of awareness about reproductive health, human rights and attitudes and intentions towards FGC among women and men participating in the basic education program, among women men living in the villages and not participating in the program, among women and men in the comparison community measures of the proportion of girls aged 0-10 not cut.

Study area

Two-thirds of the 90 villages included in the GTZ-supported project are in the Department of Kolda, and the remaining one-third is in the Department of Sédhiou. The predominant ethnic group is Pulaar, followed by the Mandingo ethnic group. Out of these 90 villages, 20 were chosen for inclusion as the intervention villages in the operations research study from both the Departments of Kolda and Sédhiou, according to ethnic and demographic criteria. The selection was made on the following criteria:

- Main language (Pulaar or Mandingo)

- Health area

- Department

- Size of the population

The sampling technique used to select the 20 villages was based on the proportion of these criteria within the 90 villages selected by TOSTAN. The same proportions of ethnic group, 
health area and Department found at the 90-village level was replicated at the 20-village level. Twenty other villages were selected to serve as the comparison group from the Department of Vélingara, which is, with Kolda and Sedhiou district, the third district of the Kolda region. The 20 villages were selected because they were far enough away from the intervention sites to avoid contamination, but similar enough to provide a valid comparison, and no major community-based educational intervention was present. The selection was based on the "similarity quotas" method to match with the 20 experimental villages in terms of size and ethnicity.

\section{Sample Size}

To test the hypotheses, representative samples of program participants, non-participants and residents in the comparison villages were recruited for the study. It was estimated that approximately 30 women per village would participate in the program, thus giving a total of 600 women for the group of 20 intervention villages. In addition, a maximum of ten men per village were included in the program by TOSTAN ${ }^{1}$ (as requested by the communities), giving a total of 200 men for the group of 20 intervention villages. These two groups of respondents were to be followed over time, with the same group of individuals interviewed at baseline, immediately post-intervention and at endline.

The women and men to be interviewed were to have been identified from the original listing of participants established by TOSTAN and the villages. However, after this listing was given to the research team and the interviews held, many changes were made in terms of who actually participated in the program. Consequently, the baseline samples for both women and men represent a mixture of those who did and did not subsequently participate in the program. This is not a problem because, for the baseline, this distinction is not important. As seen on Table 1, for the post-intervention and endline surveys, approximately 17 women and 4 men participants per intervention village were interviewed. These smaller numbers were largely due to participants' absence from the village during the time when the postintervention survey was undertaken because of migration. For these follow-up surveys, approximately ten women and their partners per intervention village were also randomly selected from households in which no women or men participated in the program to represent those people in the village who were 'indirectly' exposed to the program. These samples were recruited to assess the extent to which the information communicated through the program was diffused to non-participants. The selection of the households in the baseline and endline surveys was on a random basis and independent from each other. In the comparison villages, approximately ten women and their partners were randomly selected and interviewed during the baseline and endline surveys.

All respondents' daughters aged from 0 to 10 years at the time of the survey were systematically included in the study through questions asked to their parents about whether the daughter had been cut or not - this was the key outcome indicator of the program's impact. These proportions were compared over time as well as between intervention and comparison groups.

\footnotetext{
1 It is important to highlight that when the project was being planned, men were not expected to attend the classes because the TOSTAN program targets women. However a couple of weeks before the baseline survey started, TOSTAN decided to encourage 10 men in each village to participate in the program. An adjustment to this new situation was needed.
} 


\begin{tabular}{|c|c|c|c|c|c|c|c|}
\hline \multirow{3}{*}{ Indicators } & \multicolumn{5}{|c|}{ Intervention group } & \multicolumn{2}{|c|}{ Comparison group } \\
\hline & \multirow[t]{2}{*}{ Baseline } & \multicolumn{2}{|c|}{ Post-intervention 1} & \multicolumn{2}{|c|}{ Endline } & \multirow[t]{2}{*}{ Baseline } & \multirow[t]{2}{*}{ Endline } \\
\hline & & Participant & Non participant & Participant & Non participant & & \\
\hline Women (N) & 576 & 350 & 194 & 333 & 200 & 199 & 200 \\
\hline $\operatorname{Men}(\mathbf{N})$ & 373 & 85 & 198 & 82 & 185 & 184 & 198 \\
\hline Daughters (N) & 895 & 513 & 315 & 552 & 307 & 396 & 340 \\
\hline
\end{tabular}

\section{Data collection and analysis}

Quantitative Survey. Three questionnaires were used in the quantitative surveys:

- A questionnaire administered to all women who agreed to take part in the survey whether or not they had participated in the education program (in both intervention and comparison groups);

- A questionnaire administered to men participating in the program and who agreed to take part in the survey (only in intervention groups);

- A questionnaire administered to men who had not themselves taken part in the program, husbands of the women participating in the program, and who agreed to take part in the survey in the intervention group. In the comparison group partners of women interviewed were also included.

Two different questionnaires were used for men, as initially the rationale for including men in the survey was to test the effect of the wife's participation on the husband's attitude and behavior. However, given that TOSTAN included men in the classes, the direct effect of exposure to the program had to be assessed. Therefore a questionnaire for male participants was developed, identical to the one for women.

For the baseline survey, the listing of participants established by TOSTAN for each village was used to select men and women eligible for interview as participants. The second step was to interview their husband. Out of the remaining households in the village that had no participants, 10 women and men were randomly selected.

For the second and third surveys, women and men were identified from the list of participants provided by the village facilitator and key informants confirmed their participation status. However a number of women and men couldn't be traced as they had moved to other areas of the region. In particular the third survey coincided with a drought season, which had a direct effect on temporary migration to cities.

All respondents in the intervention group baseline survey were analyzed together, whether they were participants or not, because at that point in time they were all equivalent in not having been exposed to the intervention. For the post intervention and endline surveys, however, the samples for participants and non-participants were analyzed separately to be able to evaluate the effect of the intervention on participants as well as the non-participants. Chi square tests were carried out to estimate the significance of the differences observed using the 95 percent level of significance. Comparisons between most of the indicators were made in the following way:

1. A comparison between the baseline survey and the immediate post-intervention survey for women and men who had participated in the program; 
2. A comparison between women and men who had participated in the program and women and men who had not participated living in the same village, i.e. who had been indirectly exposed to the program;

3. A comparison between women and men who had participated in the program in the two post intervention surveys;

4. A comparison between the women and men indirectly exposed to the program in the two post intervention surveys;

5. A comparison between baseline and endline surveys in the comparison group; for indicators that also changed over time in the comparison group, a statistical test ( $\mathrm{z}$ test) was conducted to compare differences in the changes between the intervention and comparison groups to identify whether the changes in the intervention group could be attributed to the education program over and above any endogenous changes in the areas. A 95 percent confidence level was used.

6. Life tables were used to examine the occurrence of female genital cutting in the group of daughters aged from 0 to 10 at two periods of time, baseline and endline. A logrank test was used to compare survival curves of the two groups of girls.

In the tables that follow, all significant values are marked with ${ }^{*} \mathrm{p}<0.05$ and $* * \mathrm{p}<0.001$. Significant numbers shows a statistical difference between the marked number and the number preceding as demonstrated in the above description.

Qualitative Survey. The community mobilization process and people's perceptions, attitudes and behavior were also measured by collecting qualitative data. It was essential to observe the situation in the villages before introducing the intervention so as to be able to detect any possible changes over time. To collect this qualitative data a sub-sample of 12 villages was chosen for the baseline survey from within the 20 intervention villages, of which seven villages were included in the endline survey. In selecting the villages, account was taken of the imbalance in the location of the 20 villages between Kolda (2/3) and Sédhiou (1/3) districts, between the Pulaar and Mandingo ethnic groups, and the size of the population. Karcia was added at the endline survey because it hosted the public declaration. Ethnographic methods were used, taking into account the socio-cultural and ethnic context. Two strategies were used:

- Ethnographic observation in each of the 12 villages. A qualitative researcher participated in villager's life for 3 weeks, observed and conducted non-formal interviews. Several reproductive health, human rights and hygiene themes were explored.

- From the information collected, semi-structured questionnaires were developed, key informants identified and social mapping of the villages.

The following were interviewed:

- Male and female resource persons and community leaders. These included village chiefs, rural counselors, imams, traditional healers, presidents of the women's group and the management committee;

- Women and men who had participated in the village empowerment program (VEP);

- Traditional "excisors"; and,

- The twenty facilitators who had directed the classes. 
Group discussions with leaders, groups of women participants and groups of men participants, and groups of men non-participants were organized in these villages during all three phases of the intervention.

Table 2: Qualitative data collection

\begin{tabular}{|l|c|c|c|c|}
\hline Methods & Baseline & Post Intervention & \multicolumn{2}{|c|}{ Endline } \\
\hline Informal talks & 42 & & \multicolumn{2}{|c|}{ Exp } \\
\hline Non structured talks & 130 & $10^{*}$ & 20 & 11 \\
\hline Semi-structured talks & 62 & 20 & 6 (93 persons) & 2 (33 persons) \\
\hline Focus group & 7 (64 persons) & $2 *(30$ persons $)$ & & \\
\hline
\end{tabular}

* These talks were related to the public declaration process

\section{Results}

\section{Participation in the program}

Before the study, TOSTAN provided a listing of the women and men in the 20 villages who had expressed interest in participating in the program. By the time the program started, however, only 64 percent of the women and 50 percent of men who had expressed interest actually did so. People didn't attend the program for several reasons: men failed to participate because they found that no economic compensation was provided and women because classes were too overcrowded, they got sick or pregnant, or because their husband forbade it.

The lower level of participation by the men was the result of a decision by TOSTAN, as the education program was developed originally to empower women. However, TOSTAN recognized not including men created problems among them, who felt their exclusion was not fair.

With the exception of one village (Karcia), all villages experienced men dropping out of the program, including one village where all nine men who said they would participate in the program dropped out. According to an informant in this village, this was because: "the facilitator did not choose the best way of introducing the theme about the practice of FGC. The village head didn't like this theme, and he called for the center to be closed. The idea of destroying the hut and attacking the supervisor came up on the day a baptism was being celebrated in the village. The people thought the program was coming to fight against the traditional culture, which had come down from their forefathers, and even more to fight against the principles of Islam and the purification of the woman."

According to the facilitator "several meetings had been held to discuss carrying out the TOSTAN program in the village, up to the day when the son of the president of the women's group turned up and demanded that the hut should be torn down at once and the facilitator expelled."

\section{Participation and Interest in the Program's Modules}

Overall, 69 percent of the women and 57 percent of the men who participated in the program completed all four modules, with the remainder completing part of the program. Among those who did not complete the whole course, human rights and hygiene were the most attended modules, and problem solving was the least popular (see Table 3 ). 
Table 3: Proportion of participants that partially completed the program by modules completed

\begin{tabular}{lccccc}
\hline \hline Modules & $\begin{array}{c}\text { Human } \\
\text { Rights }\end{array}$ & Hygiene & $\begin{array}{c}\text { Women's } \\
\text { health }\end{array}$ & $\begin{array}{c}\text { Problem } \\
\text { solving }\end{array}$ & $\mathbf{N}$ \\
\hline Women & 69 & 68 & 53 & 31 & $\mathbf{1 0 8}$ \\
Men & 57 & 84 & 62 & 24 & $\mathbf{3 7}$ \\
\hline \hline
\end{tabular}

The reasons given by the men for not following the program completely were travel and lack of time. For the women, the main reason was also travel, followed by illness, pregnancy and lack of time. The timing of the modules on problem solving and women's health coincided with the pre-harvest period, which is the period of greatest agricultural activity for women, which explains partly their absence.

Participation in the modules by those who completed the whole course is described in Table 4. Those who followed the whole program seemed particularly interested in the course on hygiene and were less interested in the module on problem solving.

Table 4: Participation by module of participants that attended the complete program

\begin{tabular}{lccccc}
\hline \hline Modules & Hygiene & $\begin{array}{c}\text { Human } \\
\text { Rights }\end{array}$ & $\begin{array}{c}\text { Women's } \\
\text { health }\end{array}$ & $\begin{array}{c}\text { Problem } \\
\text { solving }\end{array}$ & N \\
\hline Women & 84 & 76 & 76 & 44 & $\mathbf{2 4 1}$ \\
Men & 81 & 81 & 70 & 49 & $\mathbf{4 7}$ \\
\hline
\end{tabular}

\section{Participants' expectations and benefits}

Nearly 9 women out of 10 - and nearly 4 men out of 5 - expected to increase their knowledge, especially about hygiene, health, living within society, and the law. It has to be noted that 16 percent of women and 18 percent of men hoped to find a job and some of them $(8$ percent of women and 2 percent of men) hoped to get some money out of it.
"I can see that the program made us more aware of the needs of hygiene - with the ban on washing near the well, or the need to disinfect the water. In the field of health, there has been an improvement in prenatal care, according to the nurse. The yards are kept clean. The children are better looked after. They are washed and kept in clean clothes. In the village, there is more solidarity among the people, who get on better and act as one. You can see that in the garden, which the people look after. There have been fewer quarrels this year. Human relations are more relaxed and friendly. I see that a hygiene committee has been set up to keep everything clean. But what has struck me the most is the number of girls - many more than in other years - who are now in school in the C1 class. About 25 or 27 of them. That shows that their parents have been made aware of the right to education." (Primary School Head, Sakar)

After the intervention, both men and women said that the program fulfilled their expectations. Speaking of the benefits from having participated in the program, 77 percent of the men and 66 percent of the women highlighted their deeper knowledge. Many women also pointed to improved behavior in society ( $54 \%$ ), better management of one's life (52\%), and looking after one's family better $(50 \%)$. Nearly a quarter of the women said that they

"Before a whole month could pass without my giving my wives even the means of buying a Maggi cube. But now, I do all I can to help them meet their daily expenses. The men even take the women to the hospital.[...] Men respect women more, we listen to them and take their views into account." (Mandingo, polygamous woman, 28 years) could communicate better, and 
protection of their rights was mentioned by 17 percent of women. For the men, apart from an increase in their awareness and better behavior in society, the adoption of new attitudes within the family was noted.

\section{Sample Characteristics}

\section{Women}

Appendix 2 includes tables describing selected socio-demographic characteristics of the women and men sampled. The level of literacy among the women was very low in this area; fewer than half of the women interviewed had taken part in a literacy program. It should also be noted, however, that there were few literate women among those who lived in the intervention villages but did not take part in the program.

The predominant ethnic group was the Pulaar, which formed two-thirds of the sample and the Mandingo group formed more than a third of the sample. Most of the women were Muslim and most were married. Nine out of ten people in the sample were living with a partner. The characteristics of the samples remained equivalent across all three surveys, except for the age structure, in which more non-participating women under the age 20 were interviewed during the post intervention survey. The median and mean ages of those interviewed were higher during the post intervention surveys. This is probably due to the fact that, at the beginning, the people did not fully understand the purpose of the program, and thought it was something to do with girls' education. Very young girls had been selected as likely beneficiaries of the program in the beginning but as noted above, the women that actually participated, and so were interviewed in the post intervention and endline surveys, were older.

\section{Men}

The majority of the men had not gone to school, but those who participated in the program had a higher level of education and were more literate than the other men, in both groups. The Pulaar were in the majority, especially in the comparison group. The men were Muslim and mostly married, although there were more unmarried men in the intervention group than in the comparison group. A high proportion of unmarried men took part in the program. It should also be noted that in the comparison group, the numbers of those who had participated in a training program doubled between the baseline survey and the final evaluation survey. The men who took part in the program were younger, with an average age of 29, than other men in the intervention group or in the comparison group, whose average ages were, respectively, 43 and 42 . 


\section{Contribution of the Program to Awareness, Attitudes and Behavior}

\section{Human Rights}

Awareness

Participants in the program considerably increased their awareness of human rights. Between the two surveys (Baseline and Post), there was an increase of 83 percentage points for women and 51 points for men (see Figure 1). The same level could be observed a year later. At

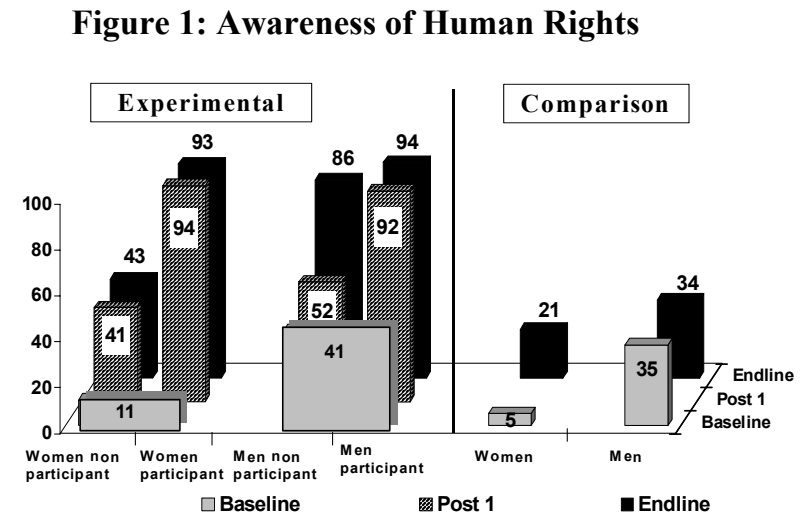
the baseline survey, the level of awareness of human rights was much higher among men than it was among women. This could be explained by the greater political involvement of men, and their greater presence in decision-making bodies, and also by their higher level of education.

It should also be noted that there was a significant increase among women and men who had not taken part in the program, but who were living in a village where the program had been implemented. TOSTAN actively encouraged each woman who took part in the program to "adopt" another person in her village and to share with her the information acquired. This phenomenon of N'Dèye Dikké is well developed in Wolof society.

There was little significant change in the replies between the post-intervention and endline surveys. However, non-participant men dramatically increased their awareness at the endline while non-participant women did not. Awareness increased in the comparison group among women, though to a lesser degree, rising from 5 percent to 21 percent (see Figure 1). This increase could be largely explained by TOSTAN's program on the regional radio about rights and health. These radio programs covered the whole region and the people living in the comparison villages could have heard them.

More than 90 percent of the women in the intervention group who participated in the post intervention and endline surveys were aware of their rights to health, education, drinking water, food, a clean environment, marriage and work. The percentage of awareness did not change much between the two periods of post intervention surveys. There was a slight fall in awareness of rights to eligibility to vote, drinking water, food and work

“There was a 'set setal' (to make oneself and one's neighborhood clean) once a week in the village. The women participants in the TOSTAN classes called a meeting each week with the village chief, in the presence of the imam, to give information about this. Each week, a day was appointed to clean up the whole village.

Everyone joined in doing this." (Woman Participant, 20 years, intervention group, 2002) and a slight increase in the awareness of the right to a clean environment, which rose to 100 percent.

\footnotetext{
${ }^{2}$ Ndeye Dikké is the name given to a person that is adopted as a friend, counselor, or confidential person.
} 
Among the women who did not take part in the program there was also some significant improvement of their awareness of their five rights - to vote, health, education, drinking water and a clean environment (from $74 \%$ to $81 \%$ ). Thus, the effects of sharing information within the village during the period between the post intervention and endline surveys appeared to work well.

"The program enabled us to look after our environment better. No more dirty water, for example, and household rubbish was better dealt with, which helped to save us from some diseases." (Non-participating woman, 30 years old, intervention village, 2003)

The difference between the intervention and comparison groups over time was significant for both spontaneously mentioning awareness and for awareness after prompting, and so it can be concluded that the basic education program did increase awareness of human rights among both men and women, though the change was greater among women. TOSTAN's radio programs, perhaps with other factors like the rotating weekly market, have contributed to increased awareness in the comparison group, however at a lower level.

\section{Attitudes towards women's rights}

As can be seen in Table 5, women in the intervention groups, participants and nonparticipants, significantly improved their attitudes towards both schooling for girls and the role of women's unions to demand rights immediately after the intervention, and these levels were sustained through to the endline. There was a significant difference between the participants and non-participants at the post intervention survey. However, it is important to note that the comparison group also revealed similar significant trends, suggesting that although the program has had an effect, it does not seem to be any greater than that created by social factors in the community.

Table 5: Attitudes of women towards women's rights issues

\begin{tabular}{|c|c|c|c|c|c|c|c|}
\hline \multirow{3}{*}{ Indicators } & \multicolumn{5}{|c|}{ Intervention group } & \multicolumn{2}{|c|}{$\begin{array}{c}\text { Comparison } \\
\text { group } \\
\end{array}$} \\
\hline & \multirow[t]{2}{*}{ Baseline } & \multicolumn{2}{|c|}{ Post-intervention } & \multicolumn{2}{|c|}{ Endline } & \multirow[t]{2}{*}{ Baseline } & \multirow[t]{2}{*}{ Endline } \\
\hline & & Participant & $\begin{array}{c}\text { Non } \\
\text { participant } \\
\end{array}$ & Participant & $\begin{array}{c}\text { Non } \\
\text { participant }\end{array}$ & & \\
\hline$(\mathrm{N})$ & 576 & 350 & 194 & 333 & 200 & 199 & 200 \\
\hline $\begin{array}{l}\text { A girl ought to go to } \\
\text { school }\end{array}$ & 76 & $99 * *$ & $96 * *$ & 100 & 98 & 57 & $100^{* *}$ \\
\hline $\begin{array}{l}\text { Women's union to } \\
\text { demand rights }\end{array}$ & 9 & $95 * *$ & $86 * *$ & 97 & 87 & 4 & $95 * *$ \\
\hline
\end{tabular}

* Significant difference $\mathrm{P}<=0.05$

** Significant difference $\mathrm{P}<=0.001$

The men too supported the policy of leaving the women free to express their opinions. From only 8 percent at the baseline survey among participating men, this went up to 89 percent by the post intervention survey and 95 percent by the endline survey. In the comparison group this also went up, from 13 to 59 percent, though the intervention group increased significantly more than the comparison over time. 
It is important to note also that quantifiable indicators on attitude and application of human rights were not easy to develop. Information from key informants and observation in the villages shows important movement towards the creation of a healthy environment, and a greater willingness to defend women's rights in the experimental area.

\section{Gender-based violence}

\section{Awareness of the concept of violence}

The proportions of women and men aware of at least one type of gender-based violence in the intervention group doubled after the start of the program (44 percent to 91 percent for women and 49 percent to 95 percent for men). It increased significantly among both the participating and non-participating women and men, and this awareness remained high at the endline (see Figure 2).

In the comparison group, the level of awareness also increased significantly. Information-sharing among peer groups, TOSTAN's radio programs and other interventions might have helped to bring information and awareness to people in the comparison group.

Differences in awareness were Figure 2: Awareness of Violence

"Violence in our neighborhood is due to a lack of communication among people. This lack of communication is the cause of all the conflicts between our husbands and us. We're just there to obey their orders and take our children to the clinic when they're ill. Thanks to the training we got from TOSTAN, we now know what we ought to do." (Woman participant 2002)

significantly greater among men in the intervention group than in the comparison group, but no significant differences were found between the women's groups.

\section{Experiences of violence}

Approval of gender-based violence was very low among all men and women: from 23 percent to 1 percent for men and from 4 percent to 3 percent for women. The proportion of those stating that there was violence in the villages dropped significantly following the program among both participants and non-participating women, but also among those in the comparison group (see Table 6). Among men, no change was observed in intervention group while there was a significant increase in reporting of violence in the comparison group.
"We have been giving thanks to God ever since the TOSTAN program began here. We used to be blind, but now our eyes have been opened, so that we know how to manage our lives. We used to know nothing about human rights, but now we know all about them, thanks to the training we received from TOSTAN. The village has become more hygienic, and our health depends on good hygiene. A dirty person is always getting ill. You have to be in good health to succeed in any walk of life. And men no longer lord it over women. Everyone is equal. Women are aware of their obligations to men and vice versa. That's one of the advantages we have gained." (Mandingo woman in the intervention group, 2002) 
Table 6: Experiences of violence during the last 12 months

\begin{tabular}{|c|c|c|c|c|c|c|c|}
\hline \multirow{3}{*}{ Indicators } & \multicolumn{5}{|c|}{ Intervention group } & \multicolumn{2}{|c|}{ Comparison group } \\
\hline & \multirow[t]{2}{*}{ Baseline } & \multicolumn{2}{|c|}{ Post-intervention } & \multicolumn{2}{|c|}{ Endline } & \multirow[t]{2}{*}{ Baseline } & \multirow[t]{2}{*}{ Endline } \\
\hline & & Participant & $\begin{array}{c}\text { Non } \\
\text { participant }\end{array}$ & Participant & $\begin{array}{c}\text { Non } \\
\text { participant }\end{array}$ & & \\
\hline Women (N) & 576 & 350 & 194 & 333 & 200 & 199 & 200 \\
\hline Practiced in the village & 86 & $37 * *$ & $33^{*}$ & $27 *$ & 28 & 79 & $38 * *$ \\
\hline Practiced in the family & 38 & 36 & 39 & 38 & 34 & 40 & $55^{*}$ \\
\hline Personally experienced & 41 & $20 * *$ & $18^{*}$ & $13 *$ & $11 *$ & 42 & $23 * *$ \\
\hline $\operatorname{Men}(\mathbf{N})$ & 373 & 85 & 198 & 82 & 185 & 184 & 198 \\
\hline Practiced in the village & 68 & 72 & 61 & 59 & 57 & 60 & $72 *$ \\
\hline Practiced in the family & 58 & $40^{*}$ & 31 & 34 & 29 & - & 46 \\
\hline
\end{tabular}

"In the past, if your husband beat you, you just sat down and cried in a state of resignation, because of your respect for your parents who had given you in marriage. Nowadays, if your husband beats you, you are not resigned to it any more. You tell the village elders or you make a formal complaint and invoke the law. That's why we say that we used to suffer a lot from the evil of illiteracy. It's the training that has enabled us to surmount these difficulties. Men no longer have the right to mistreat women, since we have ways to look after ourselves. Even divorce is better than letting ourselves be abused by heartless men." (Participating woman, Mandingo, intervention village, 2002)

Acknowledgment by women that acts of violence were committed within the family remained much the same in the intervention group, whereas the proportion of violence reported increased significantly in the comparison group. Men in the intervention group also reported less domestic violence (see Table 6).

A comparison between the surveys shows significant declines in the proportion of women declaring that they have personally suffered violence during the last 12 months (see Table 6). This occurred in both the intervention and comparison groups. However, the intervention group declined significantly more than the comparison group.

"A lot of things have changed in environmental hygiene and in acts of violence against women. No man now dares to lift his hand against a woman, or even to insult her. (Participating woman, Pulaar, 18 years old, from the intervention group, 2002)

"TOSTAN made a great difference to our village, because now, men do not carry out violence against women. Men are aware of their rights regarding women and vice versa. There are not so many problems between men and women. The program has been a great success." (Non-participating man, Badion, from the intervention group)

What types of violence are being denounced?

Among those women who mentioned that acts of violence were still continuing, physical violence was the most widely reported in the intervention group, and this increased to 70 percent by the endline. Verbal violence was the second most reported type of violence and also increased over time. One woman described the situation in the intervention villages as follows:

"Acts of violence have gone down in the village, but they still occur. My co-wife and I went to see a man who had beaten his wife to say to him diplomatically that he didn't have the right to beat his wife. We told him not to do it again, because if the 
village heard about it, it could give him trouble. He promised us not to do it again, and said he had done it in a fit of anger. As he was a participant in the program, he had learnt all this in a TOSTAN class. There is a peace committee, which can fine the husband after any act of violence..."

In the intervention group, more than 90 percent of women and men thought that acts of violence had declined since the introduction of the TOSTAN program. Moreover, the people have become better organized and want to Figure 3: What has Changed in the Village? have institutions in place for managing disputes most villages during the endline have peace and/or conflict management committees (Figure 3).

In conclusion, the concept of violence became better known and also experience of violence was reported less over time by men and women in both the intervention and comparison groups. A

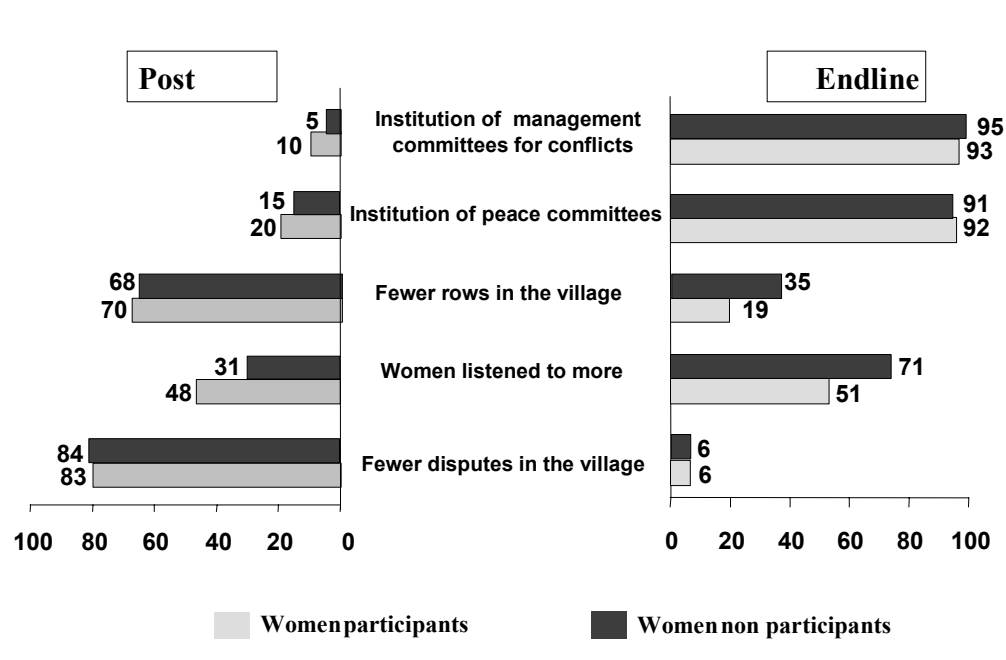
comparison of the trends in both the intervention and the comparison groups, however, showed no statistically significant differences between the two groups of women for awareness of violence and practice of violence in the village. So for both indicators it cannot be concluded that the TOSTAN program has, by itself, contributed to these changes in the experimental area, although it is thought to be the TOSTAN radio program that has influenced these changes in both areas. For both indicators related to behavior, one can conclude that the program at least contributed to the reduction of domestic violence.

\section{Knowledge and Use of Health Services}

\section{Family Planning}

After the intervention, more than 90 percent of the female and male participants, and those not participating, had heard about family planning, which was a significant increase from the baseline (see Table 7). At baseline the level of knowledge was higher in the comparison group as a result of a previous program on maternal health, but no change was observed over time for women, and a significant decrease was found among men. As a result of the phase out of this family planning (FP) program, knowledge and attitudes of men decreased significantly. 
Table 7: Knowledge and approval of family planning among women and men

\begin{tabular}{|c|c|c|c|c|c|c|c|}
\hline \multirow{3}{*}{ Indicators } & \multicolumn{5}{|c|}{ Intervention group } & \multicolumn{2}{|c|}{$\begin{array}{c}\begin{array}{c}\text { Comparison } \\
\text { group }\end{array} \\
\end{array}$} \\
\hline & \multirow[t]{2}{*}{ Baseline } & \multicolumn{2}{|c|}{ Post-intervention } & \multicolumn{2}{|c|}{ Endline } & \multirow[t]{2}{*}{ Baseline } & \multirow[t]{2}{*}{ Endline } \\
\hline & & Participant & Non participant & Participant & Non participant & & \\
\hline WOMEN (N) & 576 & 350 & 194 & 333 & 200 & 199 & 200 \\
\hline Had heard about family planning & 79 & $96^{* *}$ & $88 * *$ & 99 & 90 & 77 & 84 \\
\hline Partner approves of its use & 15 & $45^{* *}$ & $28 * *$ & 47 & 29 & 14 & 15 \\
\hline $\operatorname{MEN}(\mathbf{N})$ & 153 & 85 & 198 & 82 & 185 & 184 & 198 \\
\hline Had heard about family planning & 87 & $100 * *$ & 91 & 98 & 90 & 84 & $74 *$ \\
\hline Approved of its use by wife & 71 & 68 & 66 & 73 & 67 & 91 & $46^{* *}$ \\
\hline
\end{tabular}

Figure 4: Knowledge of Contraceptive Methods

Knowledge of contraceptive methods shows a significant increase in the intervention group for both women and men. In the comparison group a significant decrease was observed for women and no change was seen for men (Figure 4).

After the TOSTAN program, perceived partner approval of contraceptive use improved significantly among the women, although it remained less than

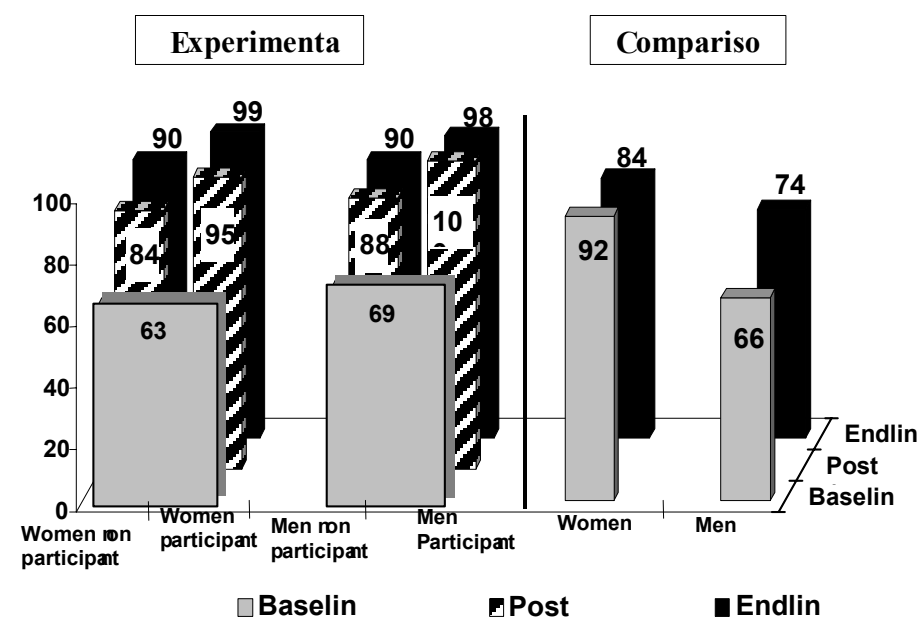
half (see Table 7). This can be explained by a better understanding of the benefits of family planning, linked to the welfare of the mother and child. Discussion with partners about family planning was reportedly much higher among the women participating (30\%) than among the non-participating women $(17 \%)$.

"There have been a lot of changes in the
village and in families. Family planning is
much better known and well approved of
nowadays because it improves the health of
the woman and of the child." (Participating
man, 28 years, member of a management
committee in the intervention group)

"If you ask a woman to space out births, it's in the interest of the family - of the mother and the child. The husband is also fed up at having to pay for the prescriptions of a sickly wife and child. My husband even gives me money, so we can go in for family planning. When we first talked about it, he refused. A month later, I raised the subject again, calmly, during the night. We managed to agree, and since then, we use contraceptives." (Participating woman, 44 years, Mandingo)

No significant improvement was observed in the comparison group for women and among men in the intervention group. However 73 percent of men participants and 67 percent of non-participant men said they approved of their wives using a method of contraception, whereas in the comparison group the proportion of men who

\footnotetext{
"Every couple has got its own system for spacing out births here, but if you know that you have problems over spacing, it's better to use modern family planning methods." (Man, 27 years, Mandingo, comparison group)
} 
approved of their wives using family planning went down significantly by half at the endline (Table 7). During the previous 12 months, very few women had used any family planning method and there was no change over time among any of the groups of women.

\section{Pregnancy surveillance and child health}

Immediately after the program, awareness about the number of prenatal consultations that a pregnant woman should have went up significantly among the female participants and those living in the intervention villages and one year later the increase was sustained. Although there was no change in the comparison group, the baseline level was significantly higher in that group than in the intervention group (Table 8) due to the maternal health and family planning program that was operating in this area.

Table 8: Distribution of women according to their awareness of surveillance of pregnancy

\begin{tabular}{|c|c|c|c|c|c|c|c|}
\hline \multirow{3}{*}{ Indicators } & \multicolumn{5}{|c|}{ Intervention group } & \multicolumn{2}{|c|}{$\begin{array}{c}\text { Comparison } \\
\text { group }\end{array}$} \\
\hline & \multirow[t]{2}{*}{ Baseline } & \multicolumn{2}{|c|}{ Post-intervention } & \multicolumn{2}{|c|}{ Endline } & \multirow[t]{2}{*}{ Baseline } & \multirow[t]{2}{*}{ Endline } \\
\hline & & Participant & Non participant & Participant & Non participant & & \\
\hline "WOMEN (N) & 576 & 350 & 194 & 333 & 200 & 199 & 200 \\
\hline At least 3 prenatal consultations & 79 & $92 * *$ & $83 * *$ & $97 * *$ & $90 *$ & 88 & 89 \\
\hline Visit during the first 3 months & 81 & $96 * *$ & $87 * *$ & 96 & $94 *$ & 88 & 93 \\
\hline Aware of symptoms of pregnancy risks & 54 & $86^{* *}$ & $78 *$ & 89 & 76 & 69 & $80 *$ \\
\hline
\end{tabular}

Women participating in the program and those living in the intervention villages increased their awareness of the importance of a first visit in the first trimester, and of the symptoms of a risky pregnancy. In the comparison group, there was also a significant increase in awareness of the symptoms of pregnancy risks but not for the need to visit during the first trimester. Women were asked at the post-intervention and endline surveys about use of antenatal care and giving birth at a health facility; the intervention group's use of services $(32 \%-34 \%)$ to give birth was significantly higher than in the comparison group (19\%).

\section{Child Survival}

By the time of the endline survey, both participating and non-participating women in the intervention villages increased their awareness of the causes of diarrhea, how to prevent diarrhea and how to treat it medically (see Table 9). In the comparison group, although there was a significant increase in awareness about the causes of diarrhea, there was no change in knowing how to prevent it and a worrying decline in the proportion of women who knew how to treat it.

Table 9: Awareness about diarrhea and its treatment

\begin{tabular}{|c|c|c|c|c|c|c|c|}
\hline \multirow{3}{*}{ Indicators } & \multicolumn{5}{|c|}{ Intervention group } & \multicolumn{2}{|c|}{ Comparison group } \\
\hline & \multirow[t]{2}{*}{ Baseline } & \multicolumn{2}{|c|}{ Post-intervention } & \multicolumn{2}{|c|}{ Endline } & \multirow[t]{2}{*}{ Baseline } & \multirow[t]{2}{*}{ Endline } \\
\hline & & Participant & Non participant & Participant & Non participant & & \\
\hline WOMEN (N) & 576 & 350 & 194 & 333 & 200 & 199 & 200 \\
\hline Know causes of diarrhea & 54 & $70 * *$ & $47 * *$ & $90 * *$ & $82 * *$ & 57 & $69 *$ \\
\hline Know how to prevent diarrhea & 53 & $76^{* *}$ & $50 * *$ & $85^{* *}$ & $72 * *$ & 58 & 59 \\
\hline Medical treatment for diarrhea & 67 & $87 * *$ & $81 *$ & 88 & $71 *$ & 77 & $56^{* *}$ \\
\hline
\end{tabular}




\section{STIs and AIDS}

As can be seen in Table 10, by the endline survey women in the intervention villages who both participated and did not participate in the program significantly increased their awareness of sexually transmitted infections (STIs). No increase was observed in the comparison group. Symptom recognition increased tremendously and there was also a significant increase in the comparison group. More men knew about at least two kinds of STI than women and again, by the time of the endline survey, the level of awareness had become very high; there was no significant change in the comparison group.

Table 10: Awareness of STI and AIDS

\begin{tabular}{|c|c|c|c|c|c|c|c|}
\hline \multirow{3}{*}{ Indicators } & \multicolumn{5}{|c|}{ Intervention group } & \multicolumn{2}{|c|}{$\begin{array}{c}\text { Comparison } \\
\text { group }\end{array}$} \\
\hline & \multirow[t]{2}{*}{ Baseline } & \multicolumn{2}{|c|}{ Post-intervention } & \multicolumn{2}{|c|}{ Endline } & \multirow[t]{2}{*}{ Baseline } & \multirow[t]{2}{*}{ Endline } \\
\hline & & Participant & Non participant & Participant & Non participant & & \\
\hline WOMEN (N) & 576 & 350 & 194 & 333 & 200 & 199 & 200 \\
\hline Knew about at least 2 STIs & 22 & $39 * *$ & $21 * *$ & $47 *$ & $30 *$ & 37 & 40 \\
\hline Knew about at least 2 symptoms & 16 & $47 * *$ & $33 * *$ & $65^{* *}$ & $52 * *$ & 27 & $47 * *$ \\
\hline Had heard about AIDS & 79 & $99 * *$ & $94 * *$ & 100 & 95 & 86 & $96 * *$ \\
\hline MEN (N) & 153 & 85 & 198 & 82 & 185 & 184 & 198 \\
\hline Knew about at least 2 STI & 59 & 48 & 38 & $83 * *$ & $76 * *$ & 66 & 70 \\
\hline Had heard about AIDS & 95 & 100 & 97 & 100 & 100 & 95 & $100 *$ \\
\hline
\end{tabular}

Among men, awareness of AIDS was almost universal at baseline, although it was lower among women. However, by the time of the endline survey, almost everyone knew about AIDS, and so it is not possible to distinguish any effect of the TOSTAN program.

Women who had participated in the program talked with their peers more about protection against AIDS than the non-participating women (53 percent as against 32\%). Abstinence, only one partner and the use of condoms were known by most of the women who had taken part in the program. Most women (80\%) who had not participated in the program did not refer to the use of condoms as a means of protection, but it increased at the end of the two years - however, as the same changes were seen in the comparison group, this improvement cannot be attributed to the TOSTAN program alone. Thirteen percent of the women did not know how to use a condom at the time of the baseline, but by the endline, there was no one in the intervention group who did not know. In the comparison group the proportions went from 6 to 4 percent.

In conclusion, levels of awareness of family planning, pregnancy surveillance, child health and STI/HIV issues increased after the program, although for many of these issues there were also significant increases in the comparison group, but to a lesser extent. However, utilization of contraception remains very low and approval by men of contraception is low. Comparisons between the intervention and comparison groups show a statistically significant increase by the intervention group for all health indicators (except the use of condoms as a means of protection). 


\section{Female Genital Cutting}

\section{Awareness about FGC}

The proportion of women who thought it necessary to practice FGC went down significantly in the intervention group immediately after the program (see Figure 5) and this trend continued one year later. Although a significant reduction was also found in the comparison group, the difference in this change was significantly less than in the intervention group.

Awareness of at least two consequences of FGC significantly increased among both men (11 percent to $83 \%$ ) and women ( 7 percent to $83 \%$ ) immediately after participating in the program, and more than half of the women who did not participate could mention at least two of the dangers of FGC after the intervention (see Figure 6). There was a significant increase also among the men who lived in the intervention villages but didn't participate in the program. These levels of awareness declined somewhat by the time of the endline survey among participating women and men, although 70 percent of women and 66 percent of men were still aware of consequences. There was no decline among the nonparticipant men living in the intervention area. However, the degree of awareness in the comparison group also increased significantly for women, but not for men. This increase is less than in the intervention group, meaning that the program brought an important change.
Figure 5: Proportion of Women Who Think that FGC is a Necessity

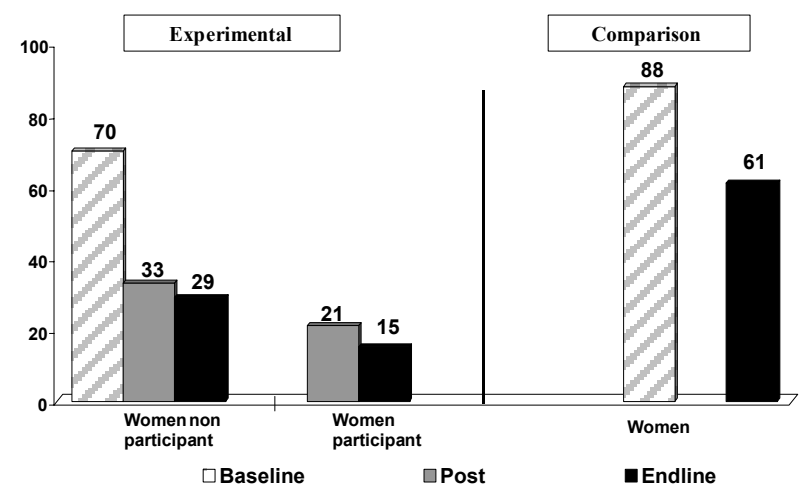

Figure 6: Awareness of at Least Two Consequences of Female Genital Cutting

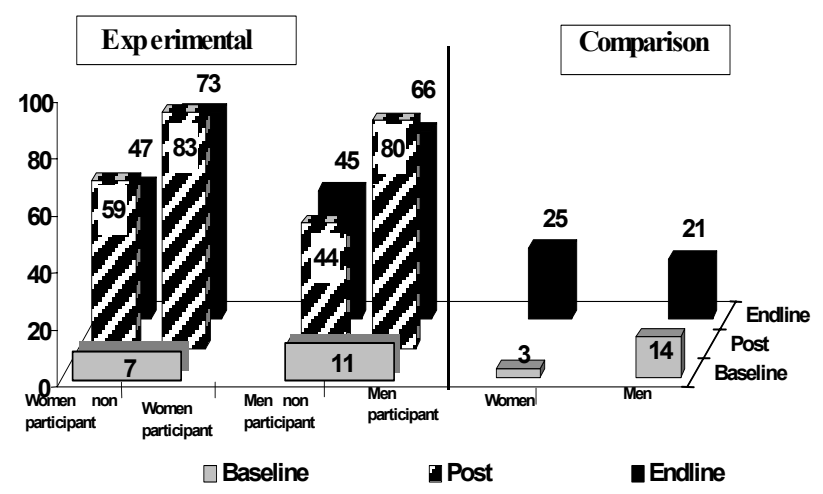

\section{FGC and religion}

The proportion of men who thought that FGC was supported by religion increased significantly among all groups in both the intervention and comparison villages, although the proportions believing this were below 50 percent (Table 11). This increase was probably due to the declarations by an important Pulaar spiritual leader made in response to the introduction of the law forbidding and punishing FGC in 1999. This statement by the spiritual leader contaminated even other ethnic groups that never practiced FGC as his argument was 
based on a Hadith that the Prophet recommended. However at endline, the level of the intervention group (34\%) believing religion supported FGC was lower than the level of the comparison group (48\%).

The Imam of Karcia gave this argument during the baseline survey: "We are Muslims. Our religion has given us clear recommendations, which we are bound to observe. It tells us: Perform the suna (circumcision) on your children when they reach the right age for it. This applies both to boys and girls." (Imam of Karcia, intervention group).

Table 11: Men's awareness of FGC

\begin{tabular}{|c|c|c|c|c|c|c|c|}
\hline \multirow{3}{*}{ Indicators } & \multicolumn{5}{|c|}{ Intervention group } & \multicolumn{2}{|c|}{ Comparison group } \\
\hline & \multirow[t]{2}{*}{ Baseline } & \multicolumn{2}{|c|}{ Post-intervention } & \multicolumn{2}{|c|}{ Endline } & \multirow[t]{2}{*}{ Baseline } & \multirow[t]{2}{*}{ Endline } \\
\hline & & Participant & Non participant & Participant & Non participant & & \\
\hline $\operatorname{MEN}(\mathbf{N})$ & 373 & 85 & 198 & 82 & 185 & 184 & 198 \\
\hline FGC is recommended by religion & 14 & $34 * *$ & $47 *$ & 34 & 40 & 25 & $48^{* *}$ \\
\hline $\begin{array}{l}\text { Awareness of at least two reasons } \\
\text { for not cutting girls }\end{array}$ & 8 & $77 * *$ & $50 * *$ & 57 & $38 *$ & 6 & $14 *$ \\
\hline
\end{tabular}

However another Imam from the same ethnic group declared, "As an Imam I haven't see anywhere in the Koran that FGC is an obligation” (Imam, Pulaar, Saré Pathé Bouya, intervention group).

\section{Approval of FGC}

The proportion of men who considered that FGC presented no advantages increased.

Knowledge of at least two reasons for not cutting girls went from 8 percent at the baseline to 77 percent immediately after the intervention among the participants and to 50 percent among the non-participants (see Table 11). These levels were maintained by the endline in the intervention group but decreased significantly in the non-participant group. In the comparison group, the proportion of men who were aware of two advantages of not cutting doubled, but this increase is lesser than that seen in the intervention group.

As seen in Table 12 between the baseline and post intervention survey, the proportion of women who approved of FGC decreased by 50 percent among the participating women, and 40 percent among the non-participating women. This decline was sustained so that by the endline survey the levels of disapproval were 16 percent and 28 percent in the two groups of women. A significant decline in approval was also found in the comparison group although the level of approval remained higher than in the intervention group. Therefore it would seem that there is a general decline in support for FGC within the region that was reinforced and accelerated by the TOSTAN program.

Perceived approval by partners decreased dramatically among women in both the intervention and comparison groups, although the decrease was significantly greater in the intervention groups (see Table 12). Indeed, perceived disapproval by husbands was lower than that of the women at the immediate post intervention survey, but by the endline survey levels of approval were approximately similar. The level of disapproval by women was higher among the Pulaar than among the Mandingo community in the intervention group. 
Table 12: Approval of FGC by women and their future intentions

\begin{tabular}{|c|c|c|c|c|c|c|c|}
\hline \multirow{3}{*}{ Indicators } & \multicolumn{5}{|c|}{ Intervention group } & \multicolumn{2}{|c|}{ Comparison group } \\
\hline & \multirow[t]{2}{*}{ Baseline } & \multicolumn{2}{|c|}{ Post-intervention } & \multicolumn{2}{|c|}{ Endline } & \multirow[t]{2}{*}{ Baseline } & \multirow[t]{2}{*}{ Endline } \\
\hline & & Participant & Non participant & Participant & Non participant & & \\
\hline WOMEN (N) & $\overline{576}$ & 350 & 194 & 333 & 200 & $\begin{array}{l}199 \\
\end{array}$ & 200 \\
\hline Approved of FGC & 72 & $21^{* *}$ & 32 & 16 & 28 & 89 & $60^{* *}$ \\
\hline Partner approved of FGC & 65 & $13 * *$ & $23 *$ & 14 & 22 & 86 & $54 * *$ \\
\hline FGC was against women's rights & - & 64 & $44^{* *}$ & $75^{*}$ & 54 & - & 25 \\
\hline Would cut daughters in the future & 71 & $15^{* *}$ & $25^{*}$ & 12 & 23 & 89 & $54 * *$ \\
\hline If it has to de done, will do it again & 34 & $11 * *$ & 19 & 10 & 15 & 48 & 42 \\
\hline
\end{tabular}

Although not measured in the baseline survey, more than two-thirds of women who participated in the TOSTAN program reported in the post intervention and endline surveys that FGC infringed on their rights, compared with only one-quarter of women in the comparison group. The difference is significant between the two groups.

\section{When did attitudes change?}

Among the majority of women participating in the program who disapproved of FGC at the endline, 85 percent said that they had changed their mind since participating in the TOSTAN program $^{3}$. Only 10 percent of these women said that their disapproval dated back several years. Of the women indirectly exposed to the program who disapproved of FGC, 64 percent attributed their attitude change to the TOSTAN program and 24 percent said their attitude change dated back one or two years. Among those in the comparison group who disapproved of FGC, 61 percent said that they had disapproved for one or two years and 12 percent said TOSTAN was responsible for their change of attitude indicating again the probable importance of the TOSTAN radio program in the region and its role in affecting the comparison group.

\section{Future Intentions}

At the baseline survey, 7 out of 10 women said they wanted to have their daughters, who had not yet been cut, cut in the future (see Table 12). This proportion fell to about one in 10 women among participants and two in 10 women indirectly exposed to the program. In the comparison group, more than half (54\%) of the women expected to have their daughters cut. Nevertheless, a significant decrease was seen here also. In the medium term, more than three quarters of the women decided no longer to have their daughters cut. But how exactly might this decision be translated into action?

\section{Regrets and future plans on FGC}

The proportion of women who do not regret having cut their daughters dropped significantly after the introduction of the program, until it settled at 10 percent for those women who had participated in the program and 15 percent for the others at endline. No significant difference was seen in the comparison group (see Table 12).

\footnotetext{
3 This was an open-ended question that assessed the timing of the change. Respondents could give any answer. Coding the question during the analysis showed that most people in the intervention group mentioned the TOSTAN program by name.
} 
There was a close correlation between disapproval of FGC and regret at having had one's daughters cut. Only one percent of women who disapproved of FGC did not regret having had their daughters cut. No woman who disapproved of FGC said she would have her daughter cut in the future. However, among the 145 women who disapproved of FGC in the intervention group and who had a daughter born during the past two years, three of them $(4 \%)$ reported having had their daughter cut.

For most women, their attitudes and those of their husband matched well. However after the intervention, 21 percent of women who participated in the program and 24 percent of the non-participating women who disapproved of FGC had husbands who either approved of FGC or had no view.

\section{Who resisted change?}

Women who still expressed a strong approval of FGC $(n=107)$ after the intervention were equally likely to come from both ethnic communities, were likely to be married and in polygamous households, and were likely to talk less about their rights. Of major concern, half of them had participated in the program. Moreover, it was more likely that their husbands had decided that they should join the program, that they did not regret having had their daughters cut, that their husbands approved of their attitude and that the husbands themselves were generally in favor of FGC. In summary these women do not have different sociodemographic characteristics than the other women who disapprove of FGC. The only characteristic that differentiates these women is the level of approval by their husbands.

\section{What is the man's point of view?}

Among all three groups of men, the proportion intending to have their daughters cut dropped significantly (see Table 13). There is a significant difference between the three groups in the magnitude of change. The change is greater in the group of men who participated directly in the program than the others. Also, the group of men living in the intervention villages (the husbands of the women participating in the program) shows a greater change in attitude than the comparison group. Consequently, it can be concluded that the program was influential on the men.

Table 13: Men's approval of FGC and their future intentions

\begin{tabular}{|c|c|c|c|c|c|c|c|}
\hline \multirow{3}{*}{ Indicators } & \multicolumn{5}{|c|}{ Intervention group } & \multicolumn{2}{|c|}{$\begin{array}{c}\text { Comparison } \\
\text { group }\end{array}$} \\
\hline & \multirow[t]{2}{*}{ Baseline } & \multicolumn{2}{|c|}{ Post-intervention } & \multicolumn{2}{|c|}{ Endline } & \multirow[t]{2}{*}{ Baseline } & \multirow[t]{2}{*}{ Endline } \\
\hline & & Participant & Non participant & Participant & Non participant & & \\
\hline MEN (N) & 373 & 85 & 198 & 82 & 185 & 184 & 198 \\
\hline Will cut daughters in the future & 66 & - & - & $13 * *$ & $32 * *$ & 78 & $56 * *$ \\
\hline Prefers a woman who has been cut & - & 21 & $42 * *$ & 20 & 40 & - & 63 \\
\hline No benefits from cutting & 15 & $60 * *$ & $35^{* *}$ & 63 & 38 & - & 32 \\
\hline Would ask the people to stop the practice & - & 78 & $59 *$ & 71 & 60 & - & 29 \\
\hline $\begin{array}{l}\text { Would support women who call for the } \\
\text { practice to be stopped }\end{array}$ & - & 85 & - & $71 *$ & 60 & - & 28 \\
\hline
\end{tabular}


According to the women, decision-making remains with the father:

"It's the women who have brought the change about. They have to discuss giving up $F G C$ with their husbands, because if a husband wants his daughter cut, the mother can do nothing." (42 year old woman, vice-president of a participating group).

Men who had participated in the program were significantly less likely than men not participating in the program to prefer a woman to be cut, and both groups were significantly less likely than men in the comparison group to have this preference (see Table 13).

\section{Perceptions on the future of the practice}

Following the TOSTAN program, approximately three-quarters of men who participated indicated that they would ask people in their communities to stop the practice and would support women calling for the abandonment of FGC. The proportion was significantly less among the men not participating in the program but was still in the majority (see Table 13). Conversely, in the comparison group, less than 30 percent of men indicated such support. Thus the TOSTAN program seems to have had a significant effect on men's willingness to publicly support abandonment of the practice.

\section{The practice and prevalence of $F G C$}

Data about the cutting of girls was obtained through interviewing women about their daughters (defined as any female child ever born to that woman). Variations in the samples of girls included in the three surveys were due to migration, marriage and death among the women.

\section{Prevalence of FGC}

As Table 14 shows, among all daughters, regardless of their age, the percentage cut was $66-$ 71 percent at the time of the baseline. The difference between the two groups was non significant. Prevalence of FGC was measured using responses concerning the sample of daughters who had passed the age at which they were considered to be at 'risk' of being cut. For the study area (Kolda), this age was estimated to be five years, as a previous study (Bop, 1999) had shown that 95 percent of girls had been cut before reaching this age.

The prevalence of FGC among daughters was high at baseline ( 87 percent - 93 percent, no significant differences). By the endline, while remaining high, there was a significant reduction between daughters of women participating to the program and daughters of women not participating in the program (see Table 14). No significant change could be seen in the comparison group. 
Table 14: Prevalence of FGC and the proportion of girls who had not been cut according to age groups

\begin{tabular}{|c|c|c|c|c|c|c|c|}
\hline \multirow{3}{*}{ Indicators } & \multicolumn{5}{|c|}{ Intervention group } & \multicolumn{2}{|c|}{ Comparison group } \\
\hline & \multirow[t]{2}{*}{ Baseline } & \multicolumn{2}{|c|}{ Post-intervention } & \multicolumn{2}{|c|}{ Endline } & \multirow[t]{2}{*}{ Baseline } & \multirow[t]{2}{*}{ Endline } \\
\hline & & Participant & Non participant & Participant & $\begin{array}{c}\text { Non } \\
\text { participant }\end{array}$ & & \\
\hline Total number of women (N) & 576 & 350 & 194 & 333 & 200 & 199 & 200 \\
\hline Total number of daughters (N) & 895 & 513 & 315 & 552 & 307 & 396 & 340 \\
\hline percent of all daughters who had been cut & 66 & 66 & 67 & 59 & $57 *$ & 71 & 70 \\
\hline FGC prevalence among daughters & $\begin{array}{c}87 \\
(n=550)\end{array}$ & $\begin{array}{c}84 \\
(n=340)\end{array}$ & $\begin{array}{c}85 \\
(n=213)\end{array}$ & $\begin{array}{c}79 * \\
(n=353)\end{array}$ & $\begin{array}{c}78 * \\
(n=199)\end{array}$ & $\begin{array}{c}93 \\
(n=272)\end{array}$ & $\begin{array}{c}89 \\
(n=232)\end{array}$ \\
\hline Girls $0-10$ years not cut & $\begin{array}{c}46 \\
(n=589)\end{array}$ & $\begin{array}{c}51 * \\
(n=320)\end{array}$ & $\begin{array}{c}55 \\
(n=174)\end{array}$ & $\begin{array}{c}60 * \\
(n=358)\end{array}$ & $\begin{array}{c}64 * \\
(n=189)\end{array}$ & $\begin{array}{c}48 \\
(n=222)\end{array}$ & $\begin{array}{c}48 \\
(n=199)\end{array}$ \\
\hline Girls over 10 years not cut & $\begin{array}{c}11 \\
(n=306)\end{array}$ & $\begin{array}{c}8 \\
(n=226)\end{array}$ & $\begin{array}{c}7 \\
(n=155)\end{array}$ & $\begin{array}{c}6 \\
(n=194)\end{array}$ & $\begin{array}{c}11 \\
(n=118)\end{array}$ & $\begin{array}{c}5 \\
(n=174)\end{array}$ & $\begin{array}{c}6 \\
(n=141)\end{array}$ \\
\hline Girls $0-4$ years not cut & $\begin{array}{c}68 \\
(n=345)\end{array}$ & $\begin{array}{c}70 \\
(n=174)\end{array}$ & $\begin{array}{c}71 \\
(n=102)\end{array}$ & $\begin{array}{c}78 * \\
(n=171)\end{array}$ & $\begin{array}{c}83 * \\
(n=108)\end{array}$ & $\begin{array}{c}77 \\
(n=124)\end{array}$ & $\begin{array}{c}81 \\
(n=91)\end{array}$ \\
\hline Girls $5-10$ years not cut & $\begin{array}{c}21 \\
(n=247)\end{array}$ & $\begin{array}{c}34 * \\
(n=146)\end{array}$ & $\begin{array}{c}45 \\
(n=78)\end{array}$ & $\begin{array}{c}49 * \\
(n=157)\end{array}$ & $\begin{array}{c}44 * \\
(n=79)\end{array}$ & $\begin{array}{c}20 \\
(n=96)\end{array}$ & $\begin{array}{c}21 \\
(n=90)\end{array}$ \\
\hline Girls under 2 years not cut & $\begin{array}{c}87 \\
(n=107)\end{array}$ & $\begin{array}{c}90 \\
(n=42)\end{array}$ & $\begin{array}{c}97 \\
(n=29)\end{array}$ & $\begin{array}{c}88 \\
(n=48)\end{array}$ & $\begin{array}{c}88 \\
(n=24)\end{array}$ & $\begin{array}{c}98 \\
(n=44)\end{array}$ & $\begin{array}{c}100 \\
(n=26)\end{array}$ \\
\hline
\end{tabular}

Sub sample of girls aged from 0 to 10 years

As Table 14 shows, the proportion of girls from 0 to 10 years old that had not been cut in the intervention group increased significantly between the baseline survey and the endline.

Although this proportion was lower than that for daughters of non-participating women, the difference between the two groups was not significant. There was no significant difference in the comparison group between the baseline and the endline. Moreover, the proportion of girls who had not been cut by the endline survey was significantly different between the intervention and comparison groups.

For those aged 10 years and above, only 10 percent in the intervention group and six percent in the comparison group had not been cut, demonstrating that in this area FGC is done before the age of 10 years. Once past that age, the risk of being cut is almost non-existent - over time, the proportion of uncut girls in this age group remains the same.

\section{Comparison of the proportion of girls aged between 0 and 4 and between 5 and 10}

Over three-quarters of girls in the age group from 0 to 4 were uncut at the time of the baseline survey, and this rose to 78 percent and 83 percent by the endline for participating and nonparticipating mothers respectively - a significant difference. In the comparison group, however, the percentage of girls aged from 0 to 4 who were uncut did not change (see Table 14).

A significant increase occurred between baseline and endline of the proportion of daughters aged 5 and 10 years old who were uncut, for both mothers participating in the program and for non-participating mothers. In the comparison group, the proportion stayed the same.

$F G C$ in the age group 0 to 2 years

Among the group of daughters aged 0 to 2 years of mothers living in the intervention villages, there were more daughters cut at the endline survey than in the comparison group (see Table 14). This suggests that women in the intervention villages who wanted to cut their 
daughters did it very early, as the timing of cutting appears to have accelerated for this group. Those women who had had their daughters cut between 0 and 2 years didn't have different characteristics from other women, except that they were all from the Pulaar ethnic group. Only eight of the women were participating in the program.

\section{The timing of $F G C$}

Data in Figure 7 present a life table analysis that makes use of information from girls' histories that were not complete because they may still have been at risk of being cut. In the intervention group, after age one year, a clear and significant trend of more girls being uncut at the endline than at the baseline was maintained right up to the age of nine years, when at endline, 63 percent had not being cut compared with 43 percent at baseline. In the comparison group, there is a non-significant difference between endline and baseline surveys, although in this group the proportion uncut is higher in the baseline than endline surveys (Figure 7).

\section{Figure 7: Proportions of girls aged 0 to 10 not cut}

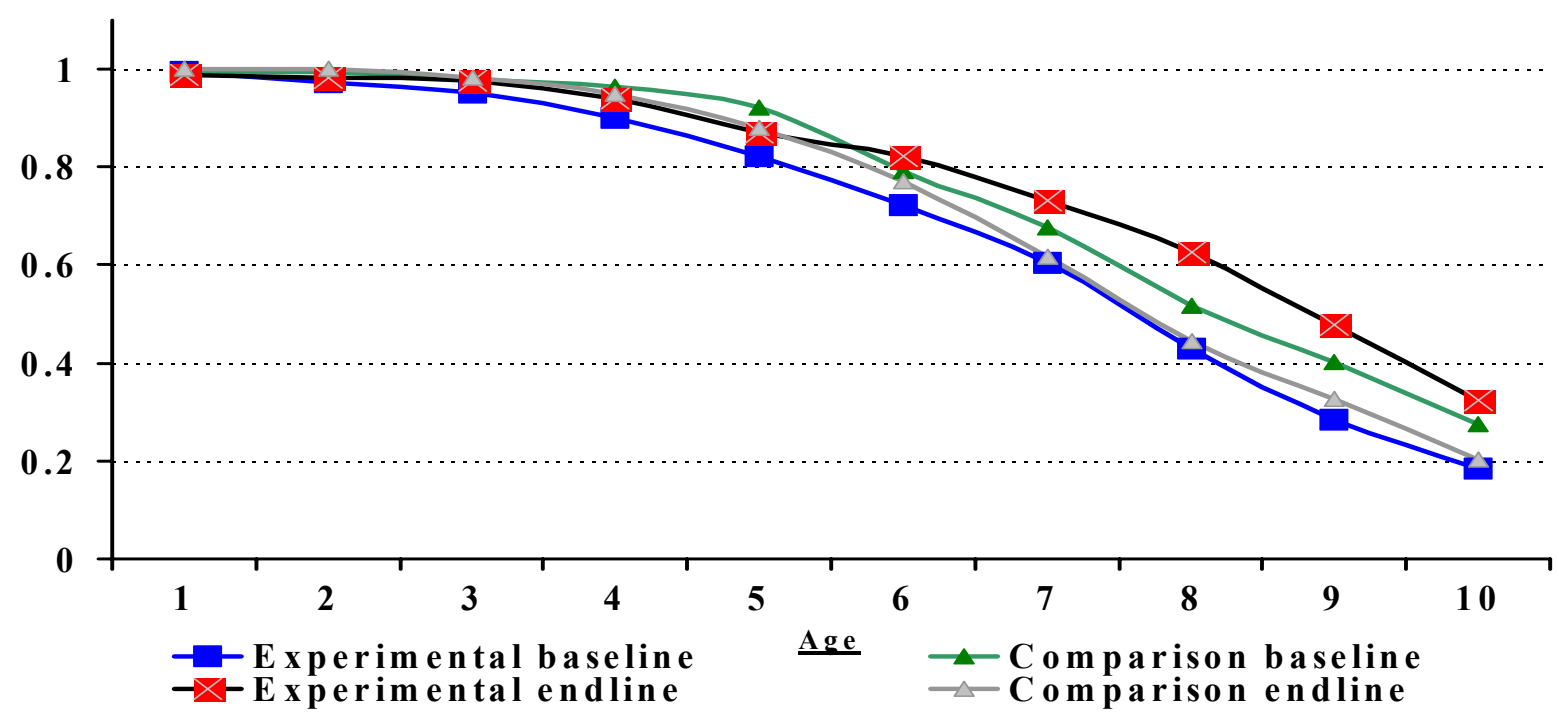

In conclusion, participation in the program did succeed in bringing about changes in attitudes towards and a reduction in the practice of FGC. More than twice as many daughters of those participating in the program survived the normal age of cutting at the endline than at the baseline. However, those few families of participants who were still cutting their daughters seem to be cutting them at a slightly younger age. Women who participated in the program were more likely to have daughters surviving than women who were indirectly exposed to it.

\section{Information about FGC}

As shown on Table 15, at the time of the baseline over half of the men and women in both the intervention and comparison groups reported having already received some information about FGC. By the time of the post-intervention survey, there was a significant increase in both groups among the female participants, but no difference among the men, and one year later 
the level remained the same. By the time of the endline survey, however, there was a significant increase among women not participating in the program. The statistical test of comparison shows that, for women, the two intervention groups have a higher level of increase $(z=5.3)$ than the comparison group. For men, however, a significant decrease was observed in the comparison area.

Table 15: Diffusion of information about Anti FGC Campaigns

\begin{tabular}{|c|c|c|c|c|c|c|c|}
\hline \multirow{3}{*}{ Indicators } & \multicolumn{5}{|c|}{ Intervention group } & \multicolumn{2}{|c|}{ Comparison group } \\
\hline & \multirow[t]{2}{*}{ Baseline } & \multicolumn{2}{|c|}{ Post-intervention } & \multicolumn{2}{|c|}{ Endline } & \multirow[t]{2}{*}{ Baseline } & \multirow[t]{2}{*}{ Endline } \\
\hline & & Participant & Non participant & Participant & Non participant & & \\
\hline WOMEN (N) & 576 & 350 & 194 & 333 & 200 & 199 & 200 \\
\hline Had received information on FGC & 64 & $94 * *$ & $76^{* *}$ & 96 & 85 & 55 & $71^{*}$ \\
\hline Had discussed FGC with others & 10 & $42 * *$ & $27^{*}$ & $92 * *$ & $68 * *$ & 5 & $49 * *$ \\
\hline $\begin{array}{l}\text { Discussion about } \mathrm{FGC} \text { in the village } \\
\text { during the last } 12 \text { months }\end{array}$ & - & 83 & $63 * *$ & $93 * *$ & $76^{*}$ & - & 1 \\
\hline Aware of the law against FGC & 72 & - & - & $93 * *$ & $88 * *$ & 62 & $75^{*}$ \\
\hline $\operatorname{Men}(\mathbf{N})$ & 373 & 85 & 198 & 82 & 185 & 184 & 198 \\
\hline Had received information on FGC & 56 & 53 & 45 & 49 & 67 & 58 & $33 * *$ \\
\hline Aware of the law against FGC & 57 & - & - & $83 * *$ & $81 * *$ & 52 & $71 * *$ \\
\hline
\end{tabular}

When asked the source of their information, 87 percent of women participants identified the TOSTAN program, and one quarter of nonparticipating women did so. However, only 36 percent of participating men and 19 percent of non-participating men obtained their information from TOSTAN; the main source cited was the radio.

"The practice of FGC has been given up, since
everyone knows about the law, which has recently
been applied in the neighborhood of Dabo, where
a whole family was put in prison. People are now
frightened, and there have been no more cuttings
for two years..." (Female participant, 18 years,
Pulaar)

A significant difference was found between women at the baseline survey and women participants at both the post intervention and endline surveys in terms of discussing FGC with others. However, although it was an expectation of the program that participants would share information on FGC with others in the community, only 42 percent of the women did this, but this increased dramatically by the time of the endline to 92 percent (see Table 15).

In the comparison group, there was also a significant increase between the baseline and endline surveys, suggesting that there were factors like the radio and discussion at the weekly market that encouraged community members to discuss the topic among themselves.

However the increase in the intervention group was significantly more $(z=4.3)$ than the increase in the comparison group, suggesting that the intervention had an additional impact.

A marked difference between those living in the intervention villages and those in the comparison villages can be seen, however, in the public discussions about FGC. There was virtually none at all in the comparison sites but widespread reporting of public discussions by both participants and non-participants (see Table 15) in the intervention villages. This indicates that the program achieved its intention of encouraging communities to openly discuss FGC following the TOSTAN educational sessions. 
The program brought many changes to the way people, particularly women, behaved. In general, participating women interviewed had talked about this information with other people. A significant increase of 10 percent between women participating in the post-intervention and endline surveys was noted, although the difference was not significant for non-participating women.

Awareness of the law against FGC increased significantly, both in the groups living in the intervention villages as well as those in the comparison villages (see Table 15).

Over three-quarters of women and men participants thought that the law could bring about an end to FGC. The increase in the intervention group was highly significant when compared to that of the comparison group $(\mathrm{z}=5.0)$.

\section{The Public Declaration}

The public declaration constitutes an important stage in the TOSTAN program.

On June 5, 2002, Karcia welcomed representatives of approximately 300 villages from throughout the region of Kolda to participate in the public declaration (see the text in Appendix 1).

\section{Figure 8: Awareness of and participation in the Public Declaration of Karcia}

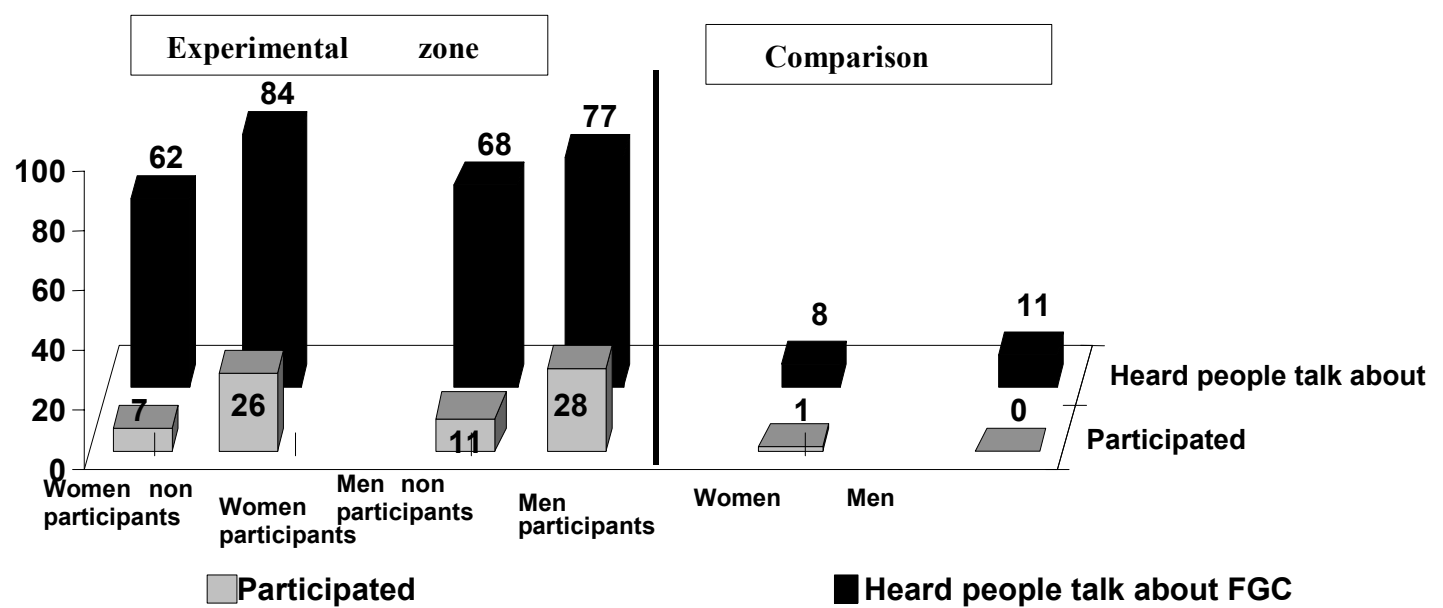

As can be seen in Figure 8, the public declaration was very well known among those living in the intervention villages, and was better known among the women. As would be expected, very few people in the comparison villages had heard about it. 
When asked about why the declaration had been made, nine out of ten women in the intervention group and 8 out of 10 in the comparison group stated that it was done to make the community, and above all the men, aware of the ill effects of FGC.

"I think that this declaration enabled people to reflect deeply on the issues of FGC, early marriage and personal violence. It was a turning point for the abandonment of $F G C$ " (Man, opinion leader, Sakar in the intervention group, 2003)

Information collected on who initiated the public declaration shows that the village leader played a key role in organizing the process for the public declaration, with the presidents of women's groups also involved for participating women and men (see Table 16). It should also be noted that the people not participating in the program felt that the TOSTAN facilitator played an important role ( 60 percent for women, 35 percent for men).

"We were all in agreement about the declaration, because it put a stop to the practice of FGC. With $F G C$, we had to face many harsh trials for our health." (Participating woman, Mandingo, 30 years, Sakar in the intervention group, 2003)

The public declaration was also seen as an opportunity to increase the popularity of the village where it was held: "It was important for the village. It enabled us to become better known” (Head of Bouya neighborhood, Karcia).

Table 16: Opinions of women and men concerning who led the public declaration

\begin{tabular}{l|cc|cc}
\hline \multirow{2}{*}{ Leader } & \multicolumn{2}{c|}{ Endline } & \multicolumn{2}{c}{ Endline } \\
\cline { 2 - 5 } & Men participant & $\begin{array}{c}\text { Men non } \\
\text { participant }\end{array}$ & $\begin{array}{c}\text { Women } \\
\text { participant }\end{array}$ & $\begin{array}{c}\text { Women non } \\
\text { participant }\end{array}$ \\
\hline Experimental & $\mathrm{N}=63$ & $\mathrm{~N}=126$ & $\mathrm{~N}=279$ & $\mathrm{~N}=123$ \\
\hline Head of village & 65 & 84 & 53 & 52 \\
Women's group president & 59 & 69 & 30 & 33 \\
TOSTAN / OFAD & 18 & 35 & 32 & $\mathrm{~N}=15$ \\
\hline Comparison & & $\mathrm{N}=22$ & & 100 \\
\hline Head of village & & 77 & & 93 \\
Women's group president & & 73 & & 93 \\
TOSTAN / OFAD & & 73 & \\
\hline \hline
\end{tabular}

As the public declaration came near, the process of diffusion of the information and social mobilization strategy, which had been helped along by the Ndeye Dikké (sponsorship) system, reached its climax. The social mobilization process was undertaken through intervillage meetings.

"During the implementation of the program in the Pakao, periodic meetings were held where each village centre was sending 2 participants. During these meetings discussions were held on the program and later on the participation and organization of Karcia declaration. We wanted to show TOSTAN that we are ready for this declaration." (Participant, focus group, 2003).

From the participants' point of view, the initiative came after having been influenced by the modules of the basic education program, but also by the previous public declaration of Mampatim. 
"This is the declaration of Mampatim which sensitized the population, because at that time nobody knew that TOSTAN would come and work in our village. This declaration brings people's awareness on the dangers of cutting. Then when TOSTAN came people were already sensitized and the program reinforced the need for abandonment of the practice." (Male participant, focus group, 2003)

Various means were used to publicize the information about the Public Declaration. At least seven out of 10 people received information through their village leader, their women's group and through friends. Others heard about it in the market place, at the mosque or through the radio.

\section{Participation in and acceptance of the Public Declaration}

In the intervention villages, many of those interviewed had heard of the public declaration, but fewer had actually taken part (see Table 17). The majority of men and women who had participated in the program and who had heard of the declaration considered that the decisions taken at the public declaration would be carried out. Those men and women exposed to the program in the villages, but who had not directly participated in it, were less likely to believe that the declaration would be observed. In the comparison group, there had been no participation in the public declaration.

Table 17: Participation in the public declaration and opinion among those who heard about it

\begin{tabular}{l||cc}
\hline \multirow{2}{*}{\multicolumn{1}{l||}{ Indicators }} & \multicolumn{2}{c}{ Intervention group } \\
\cline { 2 - 3 } & \multicolumn{2}{c}{ Endline } \\
\cline { 2 - 3 } & Participant & Non participant \\
\hline \hline WOMEN (N) & 280 & 124 \\
\hline Had participated in the declaration & 69 & 7 \\
The declaration will be respected & 69 & 46 \\
No girl will be cut again & 63 & 125 \\
\hline MEN (N) & 28 & 11 \\
\hline Had participated in the declaration & 63 & 48 \\
The declaration will be respected & 57 \\
No girl will be cut again & \multicolumn{2}{|c}{44} \\
\hline \hline
\end{tabular}

The male and female participants, who took part in the public declaration, strove to disseminate information on the dangers of FGC and early marriage to the rest of the community. The event was, above all, a way of making people more aware and getting them to adhere to the decision of giving up FGC, early arranged marriages and violence against women.
"We were part of the program. It had given us a lot of things. We wanted to spread our new knowledge through all these events. And I think it worked. Everyone who had been there went away delighted-delighted because they knew how bad FGC and early marriages were." (Participating woman, president of a group, Karcia, 2003)

Does the Public Declaration really signify the abandonment of FGC?

"After the declaration, there won't be any practices tied up with FGC in the Fouladou or the Pakao. We have given it up altogether." (Participating woman, 50 years, Mandingo, intervention group, 2003) 
Half of those who had heard about the declaration thought that the public declaration meant a real end to FGC (see Table 17). Those women who had participated in the TOSTAN program were more convinced than the non-participating women that no more girls would be cut in the villages, but there was no difference between the two groups of men. However some men made strong statements about the issue: "It will be respected because everyone has seen enough proof in the films shown and in all the other explanations the health workers have given." (Son of the village head, Mampatim in the intervention group, 2002)

Other factors (such as the role of older men and women's acceptance of the decision as they have the power of decision) will have to be considered, if abandonment is really to become effective. Some people considered that FGC could only be gradually abandoned. They also thought that the marriage ties that exist among the villages mean that it would have to be given up simultaneously in all villages that inter-marry, so that families do not risk seeing their daughters being rejected for marriage because they have not been cut.

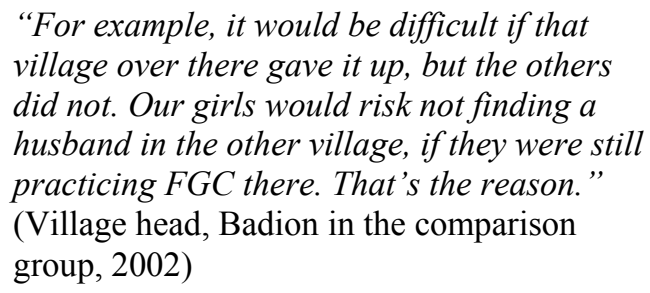
village over there gave it up, but the others did not. Our girls would risk not finding a husband in the other village, if they were still practicing FGC there. That's the reason." (Village head, Badion in the comparison group, 2002)

'It won't be all that easy. It's something we have grown up with. Perhaps gradually, when the people are made more aware. But it's always going to be difficult with the Mandinka people." (Imam of Karcia, 2003)

Few of the people interviewed in the comparison group who had heard about the public declaration thought that it would lead to the end of FGC. And the Mandingo community seem more disposed to respect what had been agreed in the public declaration and in particular the decision to give it up.

Giving up FGC may be more difficult among the Pulaar community as revealed in these remarks by an opinion former: "You know, whenever there is a problem to resolve, there are always two sides: those who are for it and those who are against it. Among us Pulaar, most people don't agree. So it follows that it won't be given up. Maybe among the Mandingo people, the declaration will be respected." (Head of Bouya neighborhood, in Karcia 2003).

\section{Sustainability of the decision}

"We think that this declaration will help people understand why we are fighting for the abandonment of the practice. They have been sensitized about the consequences of FGC. Media help us with a wide diffusion of the information. People who didn't attend the declaration were able to hear our arguments and participants and non participants in the program will be now educators when back to their home, as they are now equipped to defend their rights." (Opinion leader, Velingara Yélé, 2003).

Community members considered that for abandonment of FGC to be made permanent, it would be necessary to create certain conditions. The men believed that it was essential to ensure that the law was being faithfully observed, and also that a change of attitude would be necessary among the cutters themselves. The women thought that emphasis should be placed on making people more aware of the ill effects of FGC and that discussion groups should be set up (see Table 18).

"It's making the people and the villages more aware. That's what will bring people to do it." (Village head, Mahon, Mandingo, comparison group) 
Table 18: Opinions on what will sustain the decision to end FGC

\begin{tabular}{|c|c|c|c|}
\hline \multirow{3}{*}{ Indicators } & \multicolumn{2}{|c|}{ Intervention group } & Comparison group \\
\hline & \multicolumn{2}{|c|}{ Endline } & \multirow[t]{2}{*}{ Endline } \\
\hline & Participant & Non participant & \\
\hline WOMEN (N) & 333 & 200 & 200 \\
\hline Awareness of the ill effects of FGC & 70 & 77 & 90 \\
\hline Set up forum of discussion & 57 & 78 & 89 \\
\hline MEN (N) & 82 & 185 & 198 \\
\hline Awareness of the ill effects of FGC & 16 & 25 & 56 \\
\hline Implement the law & 83 & 77 & 91 \\
\hline Convert traditional excisors & 88 & 77 & 95 \\
\hline
\end{tabular}

The commitment of the whole community, particularly the women, was felt to be essential. In addition, those taking part in discussion groups suggested that the following must be done to sustain the decision:

- Strengthening the capacities of villagers and reinforcing past achievements by sustaining basic education

- Increasing the awareness of opinion leaders, men, community links and the media by symposia, theatrical performances and tea-debates

- Making women more aware of the ill effects of FGC

- Setting up community development projects

- Setting up income-generating activities for women in general and for cutters

- Finding a place for the cutters in the public health organization.

In conclusion, knowledge about FGC issues among both men and women increased dramatically during the period of observation. Those who participated in the education program increased their knowledge more than others living within the villages (although the belief that Islam recommends that girls should be cut increased between the baseline and the endline in the intervention group). However, opinions and attitudes of men and women improved positively. Most of them disapproved of FGC and have no intention to cut their daughters in the future. The same tendency is observed in the comparison group, but to a lesser extent, suggesting that there is a widespread shift in attitude, which this program may have accelerated in the intervention villages. However, given the potential contamination of the comparison villages through the TOSTAN radio programs, it is difficult to isolate the effects of the education program.

The prevalence of FGC among girls decreased significantly in the intervention groups, while it stayed at the same level in the comparison group. However a small proportion of women who participated in the program resisted change and appeared to still be cutting their daughters, and at an earlier age than the comparison group.

Most men and women in the experimental area heard about the public declaration, but only one-quarter of those who participated in the program attended the event. However most men and women that participated in the program thought that the declaration would be respected. The Mandingo ethnic group seems is more willing to respect the new decision. For this decision to be sustained over time, women suggested more IEC campaigns and the establishment of opportunities for discussion. Men suggested that the law should be fully implemented and the conversion of traditional excisors initiated. 


\section{A model for social change?}

The first public declaration against FGC was made at Malicounda in 1996. Since then, several public declarations have been made, including four in the Kolda Region - at Medina Cheriff with 18 villages, at Bagadadji with 105 villages, at Mampatim with 108 villages, and most recently at Karcia with 300 villages. This successful experience encouraged TOSTAN to consider the educational program, the community-wide discussions that follow, and the public declaration to be a model for enabling social change. This model (see Figure 9) includes the following phases:

Phase 1: A village committee is set up to adapt and manage the program.

Phase 2: A group of villagers (and particularly women) follow a training curriculum with four core modules.

Phase 3: Those who participate in the course select one other person with whom they share what they are learning as the program proceeds.

Phase 4: Those who took part in the educational program organize a process of social mobilization.

Public discussions are held with the community in general on subjects of interest identified by those who participated in the program so that the whole village is exposed to the intervention. The discussion leaders seek the support of the community for denouncing certain harmful practices (especially FGC and early marriage).

Phase 5: If the community expresses support, its leaders start activities to educate neighboring villages. At meetings between the villages, support is obtained from the communities with whom family ties exist.

Phase 6: A group of villages organize a public declaration to indicate their communal intention to abandon these harmful practices. The impact of the intervention depends on the number of villages that received the program, their willingness to convince other villages, and the dynamism of the leaders.

From the results presented, it is clear that the program followed all six phases of implementation. The direct exposure of women and men to the program intervention dramatically increased their knowledge, improved their attitudes and changed their behavior on most indicators. The Ndeye Dikké 'adoption' system was implemented successfully, even if the men and women that did not participate in the classes showed less improvement than those who participated in the classes, for most indicators the change in the experimental area is significantly different than in the comparison area. 
An analysis of the villages represented at the Karcia Declaration reveals three types ${ }^{4}$. Of the 90 villages in which the TOSTAN program was implemented, 77 followed the educational program and took part in the public declaration (i.e.

\begin{tabular}{c|c|c|c}
\hline \hline Villages & Education & $\begin{array}{c}\text { Public } \\
\text { Declaration }\end{array}$ & $\begin{array}{c}\text { Number of } \\
\text { villages }\end{array}$ \\
\hline A & + & + & 77 \\
\hline B & - & + & $\mathbf{2 2 3}$ \\
\hline C & + & - & 13 \\
\hline \hline
\end{tabular}
group A). The remaining 13 villages that went through the educational program did not take part in the declaration (i.e. group C). The vast majority of villages that participated in the Karcia Declaration, 223, did so without having first participated in the educational program (i.e. group B). A description of the activities that led to this categorization of villages is as follows.

\section{Creating a critical mass within the village (phase 2)}

The educational program was conducted in 90 villages. At the start of the program, it was noted that the women chosen to participate were not sufficiently widely distributed throughout the village. Their selection concentrated on:

- Women's Groups. This choice was justified on the grounds that, as organizations, these were ideal partners. But not all women in the communities were members of women's groups, and the women in these groups tended to be more in favor of social change because of interactions with outsiders. This has probably led to a selection bias in favor of those most likely to be interested in change.

- Family of the village head. In half a dozen villages, the family members of the village head were the only participants in the program, and so it is not clear how representative they were. However, being leaders, they could influence the rest of the community.

Even so, a high level of participation of women in the villages could be seen, and the program was successful in increasing their knowledge and their ability in the fields of human rights, hygiene, FGC and reproductive health. The men had a lower level of participation, but those who took part in the program also greatly increased their knowledge.

\section{Spreading information in villages where the education program was carried out (phase 3)}

Of critical importance was the expectation that women would spread the information learned within the villages. They shared the information they had obtained with their friends, their children and their husbands. This was less effective among the men who participated, as they were less inclined to share the information they acquired. The result was that knowledge, attitudes and behaviour also underwent changes among other women in the village and, to a lesser degree, other men. The model's aim to spread knowledge more widely in the intervention villages was successful. This happened in those villages that participated in the declaration (i.e. type A).

\section{Social action in villages (phase 4)}

Social action was easy to organize around themes such as public hygiene and improvement of the environment as organizing committees could be readily set up. It was much more

\footnotetext{
$4 \quad$ Dr Cheikh Niang, Departmental Head at the Institute of Environmental Science, Cheikh Anta Diop University, developed this schema at a brainstorming meeting.
} 
difficult, however, to organize for subjects concerned with harmful practices, such as FGC, as evidenced by less discussion and less willingness to organize during the implementation process. Overall, the campaign against FGC made less of an impression on the villages. Some of the village committees set up to support the social action found problems of planning and organization. The success of the social mobilization depended on the enthusiasm and ability found in these committees. Inter-village meetings, where information was shared between participants from different villages, helped the process of social action. More dynamic participants were able to influence other participants. Type A villages seem to have been more successful in implementing the social mobilization activities than type $\mathrm{C}$ villages.

\section{Spreading awareness among other villages (phase 5)}

A total of 77 villages out of 90 seem to have reached this stage. TOSTAN facilitators encouraged the leaders in each village, who wanted to bring about changes, to open discussions with the leaders of two other villages selected by themselves as "parental linkage villages." A total of 223 villages were approached by the 77 villages and brought into this process through inter-village meetings where both communities discussed and exchanged ideas. It was the family connections of the head of the women's group or of the village head that led to a success in this process.

\section{Organizing the Public Declaration (phase 6)}

The President of the Rural Community of Diannah Malari played a leading role in bringing the public declaration about, as did the presidents of the women's groups. Indeed, there was some competition among the villages for the honor of hosting the public declaration. In the case of Karcia, the village head and the president of the women's group wanted the name of Karcia to go down in history. A strong position was taken in the village of Karcia before undertaking a vigorous campaign among the other villages; Karcia was chosen during a leaders' meeting following a statement against FGC by the village head.

What were the motives of the other villages (group B) for taking part in the public declaration if they had not participated in the educational program? There are two important points to consider:

a) In addition to the other villages where the community and particularly the head of the village or the women's group president had family links, there was an imitation effect. When the village where the education program is seen to be important, it influences other villages that observe what happens and then seek to replicate the effort. Other villages do not want to be seen as behind in terms of infrastructure or thoughts.

b) The importance of the movement depends on the enthusiasm and mobilization of the core village. The 77 villages leaders dedicated their energy to the effort and were able to convince 223 other villages to participate, making it the biggest public declaration to date.

Acceptance of the declaration means that villages that participated in the public declaration, even though they had not participated in the educational program, really did accept the denunciation of certain practices, including FGC, and promised to abandon them. The extent of the undertaking can be seen as abandoning the practice or starting to fight against it. Representation of the people in these associated villages was limited, however, it was more the declaration of their leaders to join the social movement that seemed to emerge from the interviews. The views of some of the leaders, when asked about the chances of success, were 
positive, but there were some reservations about the time it would take. Most of them recognized that more education and sensitization of their villages could be needed if the complete abandonment of FGC was to be achieved. The view was also expressed that much might depend on the ethnic group involved (Mandingo or Pulaar).

\section{Why did 13 villages which had taken part in the education program not take part in the} Public declaration?

Three factors emerged which may explain why some of the villages decided not to participate in the public declaration despite having gone through the program. First, an influential spiritual leader justified FGC using a recommendation from Islam. Second, in these villages the TOSTAN facilitator had not been able to carry out the program effectively, or had been rejected by the community. Thirdly, the village head's family had been the only villagers taking part in the program.

\section{Discussion}

TOSTAN's model for social change has evolved to reflect African socio-cultural realities, where decisions are usually taken by groups, rather than individually. The process of extending the program's impact beyond the intervention villages has followed this social logic, which does not follow administrative boundaries. The logic of using interactions created by marriages among people living in different villages can be difficult to follow. In addition to the leaders, family groups are also expected to approach other villages with which they are linked by marriage, and this can involve villages that are geographically and administratively far apart.

The process of developing cooperation among neighboring villages means spreading information and drawing the attention of other communities to the dangers of FGC and the need to abandon its practice. For the 77 type A villages, using the model of stages of behavior change 5 , the public declaration served as a bridge from the "preparation" stage (of getting ready to change behavior) to the "action" stage (of actually making the change). It represents a public expression of the will to take action to change this behavior. The fact that a large number of communities and families were represented and supported the public expression gave the widespread social support needed to enable individual families to undertake the change.

But it is still necessary to question whether the 223 type B villages are really at the same stage in the behavior change process as type A villages after attending the public declaration. The involvement of the village leaders in the public declaration was an argument in itself for the people in their villages to consider. The public declaration could, therefore, serve as a catalyst for Type B villages, which in the process of changing their behavior are moving from the stage of "pre-contemplation" through inter-village meetings and discussions with families from the intervention villages to one of "contemplation" and then to "preparation." These villages need more support, however, through awareness campaigns or further education, so that they can in turn move on to the "action" stage.

At the beginning, the implementation team was not certain that a public declaration could be obtained, or which villages might be involved in it. Interviews with religious and community

$5 \quad$ See Izett and Toubia 1999. Learning about Social Change: A Research and Evaluation Guidebook using Female Circumcision as Case Study. Rainbo, New York 
leaders following the day of the public declaration showed that opinions as to its effectiveness differed within the participants of B villages. This confusion may indicate that the stages of "contemplation" or "preparation" were reached through the public declaration, rather than "action." Most leaders seemed willing, however, to commit themselves to moving to the "action" stage. However, the majority of community members in these villages still do not know what went on at the declaration, and so remain to be convinced, since only the leaders from type B villages were involved in the public declaration. Further research is needed in type B villages to find out the effect of the public declaration on the attitudes, intentions and behavior of the village members, and on what interventions could be effective in leading the villages to agree to this behavior change.

\section{Conclusion}

The TOSTAN educational program was successfully implemented in all 20 experimental villages; on average, most women who participated in the program attended all four modules. Women who didn't complete all the sessions attended mainly the human rights and the hygiene modules. Only half of the men participating followed the entire program, but most attended the hygiene module. The problem-solving module was the least well attended by both women and men, followed by the health module. For nine of 10 women, their expectations were fully satisfied, and communities also reported high levels of satisfaction during focus group discussions.

The first objective of the study was to evaluate the effect of the TOSTAN education program on women's and men's knowledge, attitudes and behavior regarding reproductive health, human rights and female genital cutting.

In terms of knowledge: The education program significantly increased awareness of women and men on human rights, gender-based violence, FGC and reproductive health. Awareness of the consequences of FGC was also higher. Indicators on awareness of contraception, pregnancy surveillance and child survival also improved. For most issues, women improved more than men, except for awareness of STIs and HIV/AIDS. Dissemination of the information provided through the education program worked well within the village, as women and men who did not participate in the program also increased their knowledge on most of these indicators. In the comparison villages there were also improvements in knowledge (e.g. human rights, gender-based violence, and FGC), but only the indicators on awareness of gender-based violence reached the same level of improvement as in the intervention villages. All other indicators show that the intervention group improved significantly more than the comparison group. However, endogenous change was also observed in the comparison area, and key informants in the comparison villages reported receiving information on these topics from the radio programs prepared by TOSTAN and broadcast throughout the region. In addition, the arrest of some traditional excisors in the region of Kolda brought people's attention to the practice and raised debate around the issue of FGC.

In terms of attitudes: Most attitudes also improved significantly. Women and men denounced gender discrimination and violence as well as FGC. There was a dramatic decrease in approval of FGC from both men and women living in the intervention villages, although 16 percent of women who participated in the program did not change their attitude. Intention to circumcise those not yet cut decreased significantly. In the comparison group, approval of FGC also decreased significantly, although not to the same extent as in the intervention group. Changes are occurring in the Kolda population as a whole, with rapidly 
increasing awareness of the dangers of the practice and the fact that it is illegal and against a girl's right to bodily integrity.

In terms of behavior: Both the intervention and comparison groups observed a decrease in reporting of violence against women. In both areas, fewer women reported having experienced personal violence by the endline, with a significantly greater decrease in the intervention group than the comparison group.

The prevalence of FGC among daughters of women participating in the program decreased overall, and the proportion of non-cut girls aged 0-10 years increased significantly. A few women participating in the program who still cut their daughters did so earlier. The change to earlier cutting was found also among women in the intervention villages who did not participate directly in the intervention.

No change in the use of contraception was observed over time, but use of antenatal care increased. However delivery in medical facilities remained low, given the inaccessibility of facilities in this region, but a significant difference was observed between the intervention and comparison groups. Several communities have mobilized around issues of peace and discrimination, as evidenced by the emergence of committees for the management of conflicts.

The second objective of the study was to evaluate the combined effects of the education program and the social mobilization process on the willingness of community members to abandon the practice of FGC. Representatives from more than two hundred and fifty villages gathered in Karcia to denounce the practice. A forum organized by young girls at the meeting was an opportunity to express their opposition to FGC as well as to early and forced marriage. Although a minority of people from the intervention villages actually attended the event, leaders that participated in the program were confident that the declaration will be respected and that no more girls will be cut in their villages. This feeling is more widespread among women than men although women that were indirectly exposed were less confident about this decision. Community members recommended that IEC campaigns should be continued and men would like to see the law applied more rigorously. Women suggested a public forum for discussion of the issue. The Mandingo ethnic group seems to be more willing to abandon the practice than the Pulaar, which may be because of a local Pulaar religious leader who is outspoken against abandonment and uses religious arguments.

The program has lead to important changes, not only in FGC, but also in hygiene, human rights and health. Expansion of the program to other villages of Senegal and within the African region should be encouraged.

\section{Programmatic implications}

\section{Content of the educational program}

Reinforcement of the education program to better integrate the issue of maternal mortality is important. The Kolda region has the highest rate of maternal mortality in Senegal and beyond improving communities' knowledge, increased use of the existing health infrastructure and qualified personnel would improve maternal health. The impressive level of social mobilization achieved through this program, especially against gender-based violence and FGC, and for improving environmental hygiene, should be extended to reducing maternal health, including promoting family planning. This can be achieved with a better collaboration between TOSTAN and the Ministry of the Health at the central and local level. 
Those who attended the TOSTAN program reported that the problem solving modules were too theoretical. Additionally, the module on health is implemented late in the program and these issues should be covered earlier in the program before villagers become busy with other activities.

\section{The start up process}

The process of negotiation with villagers before the program starts could be improved. The organization of village committees and their functioning also needs attention to improve the likelihood of their sustaining the social change process after TOSTAN has completed its program. Reinforcement of committee skills in organization, planning and supervision is important if they are to take over the social mobilization activities around hygiene, health or FGC abandonment. Therefore training of the village committee members and supervision should be included in the program. The selection of program participants also needs to be improved for greater transparency and a more democratic process for inclusion.

\section{The methodology}

Maintaining social cohesion is very important. The mix of men and women, and very young girls with older women, can inhibit some people during the classes and group interactions. Having classes for women separate from men, but with both groups gathering occasionally to exchange ideas, may achieve a better result.

The process of social mobilization within and between villages should be reinforced, as the inter-village meetings do not involve enough people, and the leaders do not give sufficient feedback on what had happened to their communities. Inter-village public discussions involving several segments of the community could help create the critical mass that the program is seeking to attain. This is particularly important for the villages participating in the public declaration that did not take part in the education program. A systematic process of sensitization of these village communities should be created, encouraging leaders to disseminate the information widely among the population of their village.

\section{Sustainability}

Community members interviewed felt that the knowledge they had gained needed to be reinforced. A solution may be to identify, while the program is ongoing, potential candidates that will be trained in educational methods. They could then become behavior change agents within their own villages when the program ends.

The program created expectations for further improvements in literacy and economic development. The reintroduction of literacy is a key element for sustainability. Income generation and micro credit programs could be developed to follow the education program to enable the new knowledge to be translated into practice.

Better collaboration between TOSTAN and other institutions working in the area of community development (including the president of the rural community committees) could improve the implementation of these recommendations. An advocacy plan for other NGOs, government departments or development partners' programs is needed to coordinate actions and develop this process of social and economic change. Including activities in annual operations plan of the region could sustain the program. 


\section{Utilization of Results by TOSTAN}

This evaluation and the replication of the program in Burkina Faso helped TOSTAN to improve its program both pedagogically and administratively for implementation in other regions of Senegal and in other African countries. Taking into account the different suggestions and feedback from the evaluators, TOSTAN implemented the following changes in the program:

1. Development and testing additional sessions on democracy based on the needs expressed by participants during the implementation of the human rights module. These sessions help participants to better understand the concept of human rights and responsibilities within a framework of democratic institutions and practices. The democracy module is now the first module of the program and lays the foundation for all future sessions of the program related to hygiene, health, problem solving and management.

2. Development and testing a more comprehensive Community Management Committee (CMC) training program to better prepare committee members for program implementation and management. This new CMC training has contributed to a villagelevel initiative for sustaining and spreading knowledge within the village and to surrounding communities.

3. Development and testing the second phase of the Village Empowerment Program, which includes literacy, math and project management skills (including training in feasibility studies, project implementation, budget development, preparation of financial reports, among others) and training for micro-credit initiatives. TOSTAN developed three new interactive workbooks to reinforce literacy skills as well as the themes learned during the first phase of the program. These workbooks include:

- From Knowledge to Action: Workbook 1 - Democracy, Human Rights, and Problem Solving

- From Knowledge to Action: Workbook 2 - Hygiene and Health

- From Knowledge to Action: Workbook 3 - Management Skills

All recent evaluations have shown that the community development provided by the program is incomplete without this crucial second phase. This phase is currently being tested. TOSTAN will soon publish the complete package for program implementation by other partner NGOs.

4. Participant workbook 1 on Democracy, Human Rights, and Problem Solving is available in Wolof, Pulaar, Mandinka, and Diola. The printing will be also done in the Guinean languages of Soussou, Malinke, and Pulaar (Guinean version).

5. TOSTAN will also publish a series of documents relating to project implementation:

- The TOSTAN program: Vision and Implementation (based on results in Senegal and other African countries). This document is a step-by-step guide for project implementation by other NGOs complete with all materials necessary for each step. This document will also include a budget guide for the program. 
- A manual for the financial management of the education program in the field, based upon experiences in five African countries.

- A description of the philosophy, steps and processes necessary to promote public declarations for the abandonment of Female Genital Cutting and other practices harmful to women's and girls' health.

- A guidebook for Community Management Committees to better follow and document community decisions, actions and impact of program.

- A workbook for each village facilitator to document class activities and actions in the community.

6. A regional training center will be built for sharing the training program with other NGOs and for the publication of documents for use in other countries. 


\section{Appendix 1}

\section{FOULADOU - PAKAW - BALANTACOUNDA DECLARATION}

We, the representatives of 300 villages in the region of Kolda (180 villages from Fouladou, 30 villages from Balantacounda, and 90 villages from Pakaw), are gathered today in Karcia, the 5th of June, 2002, to take a stance on the practice of Female Genital Cutting (FGC) and violence against women and girls.

\section{Given:}

- our education classes on human rights and responsibilities, the problem-solving process, basic hygiene and health of the person that were implemented by TOSTAN and the NGO OFAD/Nafoore with the financial support of Intact, GTZ Germany and Population Council;

- numerous testimonies of girls, women and excision practitioners themselves on the harmful effects of FGC;

- the belief of religious leaders that Islam guarantees the right to health and human dignity, especially for women and children;

- the input of heath care professionals and human rights trainers;

- the law adopted by the National Assembly on January 6, 1999, concerning violence against women and young girls, particularly FGC.

We firmly decide to abandon the practices of Female Genital Cutting and early marriages, following the example of Malicounda Bambara, Diabougou, Médina Cherif, Baliga, Bagadadji, Niodior, Mampatim, Malem Niami and Tomboronkoto.

We affirm our determination to promote and protect the health of women and children. Moreover, we reaffirm our appreciation of positive cultural traditions and stress the importance of continuing education programs that will encourage our children to become active citizens, aware of their human rights and responsibilities.

We appreciate the support of public officials, especially the Minister of Family and Small Children and the Minister of Health and Prevention. Equal thanks go to members of parliament for their continuing community activism.

Lastly, we express our gratitude to TOSTAN, OFAD/Nafoore, GTZ Germany, Intact, Population Council and Unicef for their support and encouragement of this country ${ }^{1} \mathrm{~s}$ efforts to make a better future for our citizens. Particular thanks go to the Wallace Research Foundation for financially supporting today ${ }^{1}$ s celebration.

Signed at Karcia, June 5, 2002.

\section{Description of the Declaration Day}

On June 5, 2002, representatives from 300 Mandinka and Fulani communities gathered in the village of Karcia, located in the southern region of Kolda, to declare an end to the centuries-old practice of Female Genital Cutting (FGC). Delegations from the regions of St. Louis, Dakar, Kaolack, Tambacounda, and Ziguinchor, and from Burkina Faso, in addition to members of several international organizations and the Senegalese government, all made the trip to share in this historic occasion.

Celebration co-existed with seriousness on this day as person after person from a high-school teacher to an elementary-school girl, a religious leader to a women ${ }^{1}$ s group leader solemnly testified to the 
importance of abandoning this long-held tradition. Ndjoba Djigary, president of the women ${ }^{1}$ s group in the village of Dar Es Salaam, explained that residents began examining and discussing previously untouched-subjects after participating in TOSTAN classes throughout 2001. These participatory sessions bore many fruits, today's event being one: "Today we are giving birth to a new baby, and we are naming her abandoning FGC. We are asking you, the greater community, to help us develop and raise this child," pronounced Ndjoba. The classes that Ndjoba referred to comprise a participatory education program covering human rights and responsibilities, problem-solving, and basic hygiene and health. The methodology, based on interactive traditions of dialogue, theater, poetry, song, and dance, fosters confidence among participants to tackle community problems and trust to broach previously taboo topics. As a result of TOSTAN classes, ninety participating villages have initiated community clean-ups, women ${ }^{1}$ s savings groups, health associations, and movements to abandon FGC and early or forced marriages. These ninety villages held meetings throughout the region to share their new knowledge, encouraging another 195 villages to join in their decision.

The call to community action resonated as delegations from other regions expressed their desire to similarly abandon FGC and asked for support in these efforts. A representative from the Fouta, a traditionally conservative region in northern Senegal, explained that TOSTAN is supporting her and other women who would like to abandon FGC by helping to improve their general economic and social situation, which in turn empowers them to create social change themselves.

In preparation for this public declaration, which brings the total number of villages that have publicly declared an end to FGC 708, representing 12 percent of the practicing population in Senegal.

TOSTAN and Unicef sponsored a two-day forum for young girls in the region to discuss issues that concern their future, one of which is FGC. This unique opportunity for girls to speak with their peers in other villages led to powerful testimonies: "We girls no longer want to be cut, we no longer want to be forced to marry, we no longer want to be discriminated against in school. We hope that all of that is finished, is over now." While these girls harbor hope for the future, their dialogue exposed poignant fears about dealing with the potential health consequences of FGC.

The event also included several theater pieces and songs from participants on the dangers of FGC and early marriage. The audience was extremely attentive to the point that, when the speaker system gave out in the middle of a skit, there was absolute silence among the crowd of approximately 2,000 as everyone strained to hear what was being said. The audience received an encouraging letter from Senator Hillary Rodham Clinton with equal attentiveness. Senator Clinton noted that, "An extraordinary power is unleashed when people reach out to their neighbors and find common ground. They begin to lift themselves up, and by doing so, lift up their families and their communities."

The Karcia declaration was then read to the assembly in French, Pulaar and Mandinka and representatives thanked all supporters, particularly the Wallace Research Foundation, for making the declaration possible. Closing words of encouragement came from the governor of Kolda, Abdoulaye Diallo, "By mobilizing yourselves, you have become the ambassadors working towards the end of FGC in Senegal." Media coverage of the event was excellent, with several radio emissions broadcast in the days following the declaration, as well as ten articles published in major Senegalese newspapers. 


\section{Appendix 2}

Table a: Distribution of women interviewed according to socio-demographic characteristics

\begin{tabular}{|c|c|c|c|c|c|c|c|}
\hline \multirow{3}{*}{ Indicators } & \multicolumn{5}{|c|}{ Experimental zone } & \multicolumn{2}{|c|}{ Control zone } \\
\hline & \multirow[t]{2}{*}{ Baseline } & \multicolumn{2}{|c|}{ Post-intervention } & \multicolumn{2}{|c|}{ Endline } & \multirow[t]{2}{*}{ Baseline } & \multirow[t]{2}{*}{ Endline } \\
\hline & & Participant & Non participant & Participant & Non participant & & \\
\hline "WOMEN (N) & 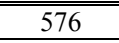 & 350 & 194 & 333 & 200 & 199 & 200 \\
\hline \multicolumn{8}{|c|}{ Level of education } \\
\hline No education & 81 & 85 & 85 & 84 & 88 & 83 & 82 \\
\hline Primary or above & 19 & 15 & 15 & 16 & 12 & 7 & 9 \\
\hline Had participated in a literacy program & 41 & 42 & 24 & 58 & 28 & 39 & 49 \\
\hline \multicolumn{8}{|c|}{ Ethnic community } \\
\hline Pulaar & 64 & 67 & 65 & 66 & 64 & 85 & 87 \\
\hline Mandingo & 34 & 32 & 31 & 33 & 35 & 8 & 7 \\
\hline Other & 1 & 2 & 4 & 1 & 2 & 8 & 7 \\
\hline \multicolumn{8}{|c|}{ Religion } \\
\hline Muslim & 99 & 99 & 98 & 100 & 99 & 99 & 99 \\
\hline Christian & 1 & 1 & 1 & 0 & 2 & 0 & 1 \\
\hline Other & 0 & 0 & 1 & 0 & 0 & 1 & 0 \\
\hline \multicolumn{8}{|c|}{ Matrimonial status } \\
\hline Married monogamously & 44 & 42 & 38 & 45 & 44 & 51 & 52 \\
\hline Married polygamously & 49 & 50 & 58 & 48 & 46 & 49 & 48 \\
\hline Unmarried and others & 7 & 8 & 5 & 7 & 10 & 1 & 0 \\
\hline
\end{tabular}

Table b:Distribution of women interviewed according to age

\begin{tabular}{|c|c|c|c|c|c|c|c|}
\hline \multirow{3}{*}{ Indicators } & \multicolumn{5}{|c|}{ Experimental zone } & \multicolumn{2}{|c|}{ Control zone } \\
\hline & \multirow[t]{2}{*}{ Baseline } & \multicolumn{2}{|c|}{ Post-intervention } & \multicolumn{2}{|c|}{ Endline } & \multirow[t]{2}{*}{ Baseline } & \multirow[t]{2}{*}{ Endline } \\
\hline & & Participant & Non participant & Participant & Non participant & & \\
\hline "WOMEN (N) & 576 & 350 & 194 & 333 & 200 & 199 & 200 \\
\hline 13-19 years & 26 & 19 & 10 & 16 & 22 & 18 & 15 \\
\hline 20-24 years & 18 & 19 & 17 & 19 & 18 & 14 & 14 \\
\hline 25-29 years & 18 & 16 & 17 & 19 & 17 & 14 & 17 \\
\hline $30-34$ years & 13 & 11 & 14 & 13 & 12 & 15 & 17 \\
\hline $35-39$ years & 8 & 10 & 11 & 11 & 14 & 10 & 16 \\
\hline 40-44 years & 8 & 10 & 10 & 11 & 6 & 11 & 12 \\
\hline 45-49 years & 5 & 7 & 11 & 8 & 9 & 9 & 7 \\
\hline $50-54$ years & 2 & 3 & 4 & 2 & 2 & 7 & 2 \\
\hline 55 years and over & 2 & 3 & 6 & 2 & 2 & 4 & 2 \\
\hline Average age & 28 years & 31 years & 34 years & 30 years & 29 years & 32 years & 31 years \\
\hline
\end{tabular}


Table c: Distribution of men interviewed according to socio-demographic characteristics

\begin{tabular}{|c|c|c|c|c|c|c|c|}
\hline \multirow{3}{*}{ Indicators } & \multicolumn{5}{|c|}{ Experimental zone } & \multicolumn{2}{|c|}{ Control zone } \\
\hline & \multirow[t]{2}{*}{ Baseline } & \multicolumn{2}{|c|}{ Post-intervention } & \multicolumn{2}{|c|}{ Endline } & \multirow[t]{2}{*}{ Baseline } & \multirow[t]{2}{*}{ Endline } \\
\hline & & Participant & Non participant & Participant & Non participant & & \\
\hline MEN (N) & 373 & 85 & 198 & 82 & 185 & 184 & 198 \\
\hline \multicolumn{8}{|c|}{ Level of education } \\
\hline No education & 69 & 60 & 73 & 51 & 75 & 80 & 75 \\
\hline Primary & 23 & 31 & 18 & 38 & 17 & 17 & 19 \\
\hline Secondary and above & 8 & 9 & 9 & 11 & 8 & 3 & 6 \\
\hline Had participated in a literacy program & 39 & 57 & 35 & 68 & 35 & 42 & 47 \\
\hline Had participated in a training program & - & - & - & - & - & 18 & 35 \\
\hline \multicolumn{8}{|c|}{ Ethnic community } \\
\hline Pulaar & 65 & 72 & 69 & 69 & 69 & 84 & 85 \\
\hline Mandingo & 34 & 27 & 30 & 31 & 29 & 6 & 10 \\
\hline Other & 1 & 1 & 1 & 0 & 2 & 10 & 5 \\
\hline \multicolumn{8}{|c|}{ Religion } \\
\hline Muslim & 98 & 100 & 100 & 100 & 100 & 98 & 99 \\
\hline Christian & 1 & 0 & 0 & 0 & 0 & 1 & 1 \\
\hline Other & 1 & 0 & 0 & 0 & 0 & 1 & 0 \\
\hline \multicolumn{8}{|c|}{ Matrimonial status } \\
\hline Married monogamously & 52 & 48 & 47 & 54 & 47 & 51 & 53 \\
\hline Married polygamously & 34 & 19 & $54 * *$ & 20 & 52 & 50 & 47 \\
\hline Unmarried & 13 & 33 & 0 & 24 & 1 & 0 & 0 \\
\hline Divorced & 0 & 0 & 0 & 1 & 0 & 0 & 0 \\
\hline Widower & 0 & 0 & 0 & 1 & 1 & 0 & 0 \\
\hline
\end{tabular}

Table d: Distribution of men interviewed according to age

\begin{tabular}{|c|c|c|c|c|c|c|c|}
\hline \multirow{3}{*}{ Indicators } & \multicolumn{5}{|c|}{ Experimental zone } & \multicolumn{2}{|c|}{ Control zone } \\
\hline & \multirow[t]{2}{*}{ Baseline } & \multicolumn{2}{|c|}{ Post-intervention } & \multicolumn{2}{|c|}{ Endline } & \multirow[t]{2}{*}{ Baseline } & \multirow[t]{2}{*}{ Endline } \\
\hline & & Participant & Non participant & Participant & Non participant & & \\
\hline $\operatorname{MEN}(\mathbf{N})$ & 373 & 85 & 198 & 82 & 185 & 184 & 198 \\
\hline $13-19$ years & 8 & 17 & 0 & 11 & 1 & 1 & 1 \\
\hline $20-24$ years & 9 & 13 & 5 & 15 & 2 & 3 & 5 \\
\hline 25-29 years & 14 & 29 & 9 & 15 & 11 & 15 & 13 \\
\hline $30-34$ years & 18 & 19 & 15 & 28 & 11 & 10 & 10 \\
\hline $35-39$ years & 13 & 12 & 16 & 16 & 17 & 14 & 14 \\
\hline 40-44 years & 12 & 7 & 12 & 5 & 10 & 12 & 19 \\
\hline 45-49 years & 9 & 2 & 13 & 10 & 11 & 14 & 13 \\
\hline $50-54$ years & 7 & 0 & 10 & 1 & 12 & 10 & 8 \\
\hline 55 years and over & 10 & 1 & 21 & 0 & 25 & 21 & 18 \\
\hline Average age & 36 years & 29 years & 43 years & 31 years & 45 years & 43 years & 42 years \\
\hline
\end{tabular}




\section{References}

Codou Bop. 1999. Rapport sur les Mutilations Génitales Féminines. CESSI, Dakar.

Direction de la Statistique, 1998. "Santé Familiale et Population ; Région de Kolda", Résultats de l'EDS de 1997.

GTZ, 2000. Community Based Reproductive Health Services in Kolda: Baseline study. Projet Senegalo-Allemand. Appui à la planification familiale et à la lutte contre les MST/SIDA "FANKANTA."

GTZ, FANKANTA, 2000. “L'excision dans la région de Kolda au Sénégal: perceptions, attitudes et pratiques", Dakar, August.

Mackie, Gerry. "Female Genital Cutting: The beginning of the end" January 1999. Oxford United Kingdom.

Ministère de la Famille, de l'Action Sociale et de la Solidarité Nationale 1999. Plan d'action National pour l'Abandon de la Pratique des MGF au Senega. Dakar, Senegal.

Mottin-Sylla, M.H. 1990. L'excision au Senegal. Serie Etudes et Recherches No 137 Enda Dakar.

Ndiaye M. Balde C. Diatta N. et al. 1993. L'excision dans la region de Kolda.. Enda Tiers Monde Actions en Casamance.

Ndiaye Salif et al. 1997. Enquête Démographique et de Santé, Senegal. Calverton, Maryland: Direction de la Statistique et Macro International, Inc.

Population Council, 2001. Frontières en Santé de la Reproduction, Evaluation d'un programme d'éducation à base communautaire, la stratégie de TOSTAN, Enquête de base, Rapport final, Dakar, Décembre.

Toubia, Nahid, and Susan Izett. 1999. Learning About Social Change: A research and evaluation guidebook using female circumcision as a case study New York: Rainbo.

TOSTAN, 1999. Breakthrough in Senegal: Ending Female Genital Cutting. Dakar Senegal.

UNDF, 1998. "Rapport National sur le Développement Humain - Senegal."

UNIFEM, 1997. Non à l'excision, Dakar Senegal.

World Health Organization. 1995. Report of a WHO Technical Working Group Meeting on Female Genital Mutilation, 17-19 July, 1995. Geneva, Switzerland: WHO. 